\title{
Induction of Thermal Hyperalgesia and Synaptic Long-Term Potentiation in the Spinal Cord Lamina I by TNF- $\alpha$ and IL- $1 \beta$ is Mediated by Glial Cells
}

\author{
Doris Gruber-Schoffnegger, Ruth Drdla-Schutting, Christoph Hönigsperger, Gabriele Wunderbaldinger, \\ Matthias Gassner, and Jürgen Sandkühler \\ Department of Neurophysiology, Center for Brain Research, Medical University of Vienna, 1090 Vienna, Austria
}

\begin{abstract}
Long-term potentiation (LTP) of synaptic strength in nociceptive pathways is a cellular model of hyperalgesia. The emerging literature suggests a role for cytokines released by spinal glial cells for both LTP and hyperalgesia. However, the underlying mechanisms are still not fully understood. In rat lumbar spinal cord slices, we now demonstrate that conditioning high-frequency stimulation of primary afferents activated spinal microglia within $<30$ min and spinal astrocytes within $\sim 2 \mathrm{~s}$. Activation of spinal glia was indispensible for LTP induction at C-fiber synapses with spinal lamina I neurons. The cytokines interleukin- $1 \beta$ (IL-1 $\beta$ ) and tumor necrosis factor- $\alpha$ (TNF- $\alpha$ ), which are both released by activated glial cells, were individually sufficient and necessary for LTP induction via redundant pathways. They differentially amplified 2-amino-3-(3-hydroxy-5-methyl-isoxazol-4-yl)-propanoic acid receptor-mediated and $N$-methyl-D-aspartic acid receptor-mediated synaptic currents in lamina I neurons. Unexpectedly, the synaptic effects by IL- $1 \beta$ and TNF- $\alpha$ were not mediated directly via activation of neuronal cytokine receptors, but rather, indirectly via IL-1 receptors and TNF receptors being expressed on glial cells in superficial spinal dorsal horn. Bath application of IL-1 $\beta$ or TNF- $\alpha$ led to the release profiles of pro-inflammatory and antiinflammatory cytokines, chemokines, and growth factors, which overlapped only partially. Heat hyperalgesia induced by spinal application of either IL-1 $\beta$ or TNF- $\alpha$ in naive animals also required activation of spinal glial cells. These results reveal a novel, decisive role of spinal glial cells for the synaptic effects of IL-1 $\beta$ and TNF- $\alpha$ and for some forms of hyperalgesia.
\end{abstract}

\section{Introduction}

Enhanced glutamatergic transmission between primary afferent C-fibers and superficial spinal dorsal horn neurons plays a pivotal role for inflammatory and wound pain. Long-term potentiation (LTP) at C-fiber synapses is an intensively studied cellular model of activity-dependent forms of pain amplification (hyperalgesia; Ikeda et al., 2003; Ikeda et al., 2006; Drdla et al., 2009; Sandkühler, 2009; Zhong et al., 2010; Kim et al., 2011; Park et al., 2011; Chu et al., 2012), but the underlying signal transduction pathways are not fully understood. An afferent barrage in nociceptive C-fibers leads to the activation of neurons and glia in superficial spinal dorsal horn. Glial cells then release cytokines, including interleukin-1 $\beta$ (IL-1 $\beta$ ) and tumor necrosis factor- $\alpha$ (TNF- $\alpha$ ). According to the prevailing view, these cytokines facilitate glutamatergic synaptic transmission between C-fibers and lamina II neurons (Kawasaki et al., 2008; Park et al., 2011; Zhang et al., 2011) by binding to their respective receptors on spinal dorsal

\footnotetext{
Received Sept. 13, 2012; revised Feb. 27, 2013; accepted March 5, 2013.

Author contributions: D.G.-S. and J.S. designed research; D.G.-S., R.D.-S., C.H., G.W., and M.G. performed research; D.G.S. analyzed data; D.G.-S. and J.S. wrote the paper.

This work was supported by Grant P22306FW from the Austrian Science Fund (to J.S.).

The authors declare no competing financial interests.

Correspondence should be addressed to Dr. Jürgen Sandkühler, Center for Brain Research, Dept. of Neurophysiology, Medical University of Vienna, Spitalgasse 4, 1090 Vienna, Austria. E-mail: juergen.sandkuehler@meduniwien.ac.at.

DOI:10.1523/JNEUROSCI.5087-12.2013

Copyright $\odot 2013$ the authors $\quad 0270-6474 / 13 / 336540-12 \$ 15.00 / 0$
}

horn neurons (Ohtori et al., 2004) or primary afferent C-fibers (Richards et al., 2011). The impact, if any, of IL- $1 \beta$ and TNF- $\alpha$ on C-fiber synapses with lamina I neurons, another key relay station for the development of hyperalgesia (Mantyh et al., 1997; Nichols et al., 1999; Ikeda et al., 2003), is presently unknown and cannot simply be deduced from the cytokine effects observed in lamina II. A given cytokine may exert diverse and even opposing effects at different types of synapses. For example, in the spinal cord, IL- $1 \beta$ or TNF- $\alpha$ may enhance frequencies and/or amplitudes of spontaneous EPSCs (Kawasaki et al., 2008; Zhang et al., 2011), but may depress C-fiber-evoked EPSCs (Youn et al., 2008) or may have no effect on basal synaptic transmission (Liu et al., 2007). The cytokines may also have no effect on LTP induction in naive animals (Zhong et al., 2010), but may induce LTP in neuropathic animals (Liu et al., 2007). In the hippocampus, TNF- $\alpha$ or IL- $1 \beta$ consistently block LTP induction (Vereker et al., 2000; Butler et al., 2004) rather than facilitate glutamatergic synaptic transmission.

TNF- $\alpha$ and IL- $1 \beta$ may be synthesized and released from microglia, astrocytes, and some types of neurons (Schäfers et al., 2003; Milligan and Watkins, 2009). Cytokine receptors may be expressed on neurons and/or glial cells (Li et al., 2005; Xu et al., 2006; Guo et al., 2007; Wei et al., 2008; Zhang et al., 2010). Therefore, cytokines do not necessarily modify synaptic strength directly by binding to presynaptic and/or postsynaptic receptors. It is equally possible that IL- $1 \beta$ or TNF- $\alpha$ act on glial cells to trigger the release of neuroactive substances, which then modify synaptic transmission and nociception. 
Here we studied the effects of TNF- $\alpha$ and IL- $1 \beta$ on synaptic transmission between primary afferent $\mathrm{C}$-fibers and spinal lamina I neurons and evaluated the role of spinal glial cells in these synaptic effects. IL- $1 \beta$ and TNF- $\alpha$ exert distinct effects on glutamatergic currents at $\mathrm{C}$-fiber synapses in lamina I and act in concert to promote LTP induction at these synapses. In contrast to the prevailing view, synaptic effects of both cytokines were mediated indirectly via activation of spinal glial cells.

\section{Materials and Methods}

All procedures were in accordance with European Communities Council directives (86/609/EEC), and were approved by the Austrian Federal Ministry for Education, Science and Culture.

Preparation of spinal cord slices. The lumbar spinal cord was removed under deep anesthesia from 22- to 26-d-old rats. Then, 500- to 600- $\mu \mathrm{m}$ thick transverse spinal cord slices with an attached dorsal root (8-16 $\mathrm{mm}$ ) were cut on a microslicer (DTK-1000; Dosaka). Slices were kept in an incubation solution that consisted of the following (in $\mathrm{mm}$ ): $95 \mathrm{NaCl}$, $1.8 \mathrm{KCl}, 1.2 \mathrm{KH}_{2} \mathrm{PO}_{4}, 0.5 \mathrm{CaCl}_{2}, 7 \mathrm{MgSO}_{4}, 26 \mathrm{NaHCO}_{3}, 15$ glucose, and 50 sucrose, and was oxygenated with $95 \% \mathrm{O}_{2}$ and $5 \% \mathrm{CO}_{2}, \mathrm{pH} 7.4$, osmolarity 310-320 mosmol/l. For the recordings, a single slice was then transferred to the recording chamber, where it was continuously superfused with oxygenated recording solution. The recording solution was identical to the incubation solution except for the following (in mM): 127 $\mathrm{NaCl}, 2.4 \mathrm{CaCl}_{2}, 1.3 \mathrm{MgSO}_{4}$, and 0 sucrose. Experiments were conducted at $32^{\circ} \mathrm{C}$.

Patch-clamp recording. Spinal dorsal horn neurons were visualized with Dodt infrared optics (Dodt and Zieglgänsberger, 1990). Lamina I neurons were recorded in the whole-cell patch-clamp configuration. Only neurons lying within a distance of maximally $20 \mu \mathrm{m}$ from the dorsal white/gray matter border were considered to be lamina I neurons. Patch pipettes (2-4 M $\Omega$ ) from borosilicate glass (Hilgenberg) were pulled from a horizontal micropipette puller (P-87; Sutter Instruments). The internal pipette solution consisted of the following (in $\mathrm{mM}$ ): 120 potassium gluconate, $20 \mathrm{KCl}, 2 \mathrm{MgCl}_{2}, 2 \mathrm{Na}_{2} \mathrm{ATP}, 0.5 \mathrm{NaGTP}, 20 \mathrm{HEPES}$, and 0.5 EGTA, pH adjusted to 7.28 with $\mathrm{KOH}$, measured osmolarity $\sim 300$ $\mathrm{mosmol} / \mathrm{L}$. Neurons were recorded in voltage-clamp mode using an Axopatch 700B patch-clamp amplifier and the pCLAMP 10 acquisition software (Molecular Devices). Signals were low-pass filtered at $2-10 \mathrm{kHz}$, sampled at $100 \mathrm{kHz}$, and analyzed offline using pCLAMP 10. No correction for the liquid junction potential was made.

Passive membrane properties. The membrane potential measured immediately after establishing the whole-cell configuration was called the resting membrane potential. Neurons with a resting membrane potential less negative than $-45 \mathrm{mV}$ were not analyzed further. Membrane resistance, membrane time constant, membrane capacitance, series resistance, and leak current were measured by means of a hyperpolarizing voltage step from $-70 \mathrm{mV}$ to $-80 \mathrm{mV}$.

Evoked EPSCs. To assess both AMPA receptor (AMPAR)- and NMDA receptor (NMDAR)-mediated currents, evoked EPSCs were investigated. In some experiments, $\mathrm{N}$-(2,6-dimethylphenylcarbamoylmethyl)-triethylammonium bromide (QX-314, $50 \mu \mathrm{M}$ ) was added to the pipette solution to prevent the generation of action potentials in the investigated neuron. EPSCs were evoked by stimulating the dorsal root with high intensities to recruit C-fibers. Afferent input was classified as being C-fiber evoked based on a combination of response threshold and conduction velocity (Chen and Sandkühler, 2000). C-fiber-evoked EPSCs were considered monosynaptic by the absence of failures during 10 consecutive pulses at $2 \mathrm{~Hz}$ and low jitter in response latencies. EPSCs and AMPAR-mediated currents were measured at a holding potential of $-70 \mathrm{mV}$. Test pulses ( $0.1 \mathrm{~ms}$ within $30 \mathrm{~s}$ intervals) were given through a suction electrode with an isolated current stimulator (A360; World Precision Instruments). NMDAR-mediated currents were measured at a holding potential of $-30 \mathrm{mV}$. Series resistance was monitored over the whole recording period. To induce synaptic LTP, suprathreshold high-frequency stimulation (HFS; 100 pulses at $100 \mathrm{~Hz}$ repeated 3 times at $10 \mathrm{~s}$ intervals) paired with current injection to depolarize the neurons to $\sim-35 \mathrm{mV}$ was applied to the dorsal root within $6 \mathrm{~min}$ after establishing the whole-cell configuration.
$\mathrm{Ca}^{2+}$ imaging in neurons and astrocytes. For fluorometric $\mathrm{Ca}^{2+}$ measurements, slices were, in single cases, first incubated in incubation solution containing $5 \mu \mathrm{M}$ sulforhodamine 101 (SR101) at $37^{\circ} \mathrm{C}$ for at least 30 min. A single sulforhodamine-loaded slice was then transferred to the recording chamber of a two-photon laser scanning microscope consisting of a Leica DM LFS microscope and a femtosecond Ti-sapphire laser operating at $90 \mathrm{MHz}$ repeat frequency, $140 \mathrm{fs}$ pulse width, and a wavelength range of 705-980 $\mathrm{nm}$. Excitation light was focused by a $40 \times$ water-immersion objective ( 0.8 numerical aperture). Excitation wavelength was set at $800 \mathrm{~nm}$. Scanning and imaging acquisition were controlled by confocal software. Emitted light was collected by a nondescanned detector for monitoring Oregon Green BAPTA and SR101. Fluorescent measurements were achieved by bidirectional scanning at a time interval of $660 \mathrm{~ms}$. Freshly made $250 \mu \mathrm{M}$ Oregon Green BAPTA-1 AM (solved in $0.5 \%$ Pluronic-127 in buffer) was pressure injected into the superficial laminae of the spinal dorsal horn. After a 15 min dye de-esterification period, imaging was started. The imaging window was always placed close to the dorsal white/ gray matter border.

In vivo field potential recordings. Experiments were performed on adult male Sprague Dawley rats. Isoflurane in two-thirds $\mathrm{N}_{2} \mathrm{O}$ and one-third $\mathrm{O}_{2}$ was used to induce (4 vol\% inspiratory) and maintain (1.5 vol\% expiratory) anesthesia. Concentrations of gases were measured and monitored with a capnograph (Capnomac Ultima; Datex-Ohmeda). The surgical level of anesthesia was verified by stable arterial blood pressure and by absence of reflex during pinching the interdigital area of the forepaw. Animals were intubated with a $14 \mathrm{G}$ cannula for mechanical ventilation with a respirator (Servo Ventilator 900C; Siemens). The right femoral artery and vein were then cannulated with a polyethylene catheter to continuously monitor blood pressure and to allow infusions of i.v. solutions. During anesthesia, animals continuously received i.v. solution (58\% Ringer's solution, 30\% HAES, $8 \%$ glucose, and $4 \%$ sodium bicarbonate, $2 \mathrm{ml} / \mathrm{h}$ ) for stabilization of blood pressure (mean 130-160 $\mathrm{mmHg}$ ), blood glucose (mean $100-120 \mathrm{mg} / \mathrm{dl}$ ), and base excess (mean $-1.5 \pm 0.8 \mathrm{mmol} / \mathrm{l}$ ). The arterial catheter was flushed every $30 \mathrm{~min}$ with a heparinized sodium solution $(2.5 \mathrm{IU} / \mathrm{ml})$ to prevent blood agglutination. Arterial blood gas analyses were performed every $30 \mathrm{~min}$. Colorectal temperature was kept at $\sim 37^{\circ} \mathrm{C}$ with a feedback-controlled heating blanket (Panlab). The left sciatic nerve was dissected free for bipolar stimulation with a silver hook electrode. The electrode was then isolated from surrounding muscles with a plastic film. A laminectomy was performed to expose lumbar segments 4 and 5. Two metal clamps were used for fixation of the animal vertebral column in a stereotactic frame. An agarose pool was formed around the exposed spinal segments. The exposed part of the sciatic nerve was covered with warm paraffin oil. Muscle relaxation was achieved by $2 \mu \mathrm{g} / \mathrm{kg} / \mathrm{h}$ i.v. pancuronium bromide. Electrophysiological recordings were performed as described previously (Drdla et al., 2009). Briefly, C-fiber-evoked field potentials were recorded with glass electrodes (impedance 2-3 M $\Omega$ ) from laminae I and II of the spinal cord dorsal horn in response to stimulation of sciatic nerve fibers. The pipette solution consisted of the following (in mM): $135 \mathrm{NaCl}, 5.4$ $\mathrm{KCl}, 1.8 \mathrm{CaCl}_{2}, 10 \mathrm{HEPES}, 1 \mathrm{MgCl}_{2}$, and $0.2 \%$ rhodamine B (Sigma). Electrodes were driven by a microstepping motor. Recordings were made with an ISODAM amplifier (Iso-Stim 01D; npi electronic) using a bandwidth filter of $0.1-1000 \mathrm{~Hz}$. Signals were monitored on a digital oscilloscope and digitized by an A/D converter. Afferent input from the hindpaw was identified by mechanical stimulation of the foot while acoustically evaluating the evoked responses with an audio monitor. Test stimuli were delivered to the sciatic nerve and consisted of single pulses of $0.5 \mathrm{~ms}$ at an intensity of $25 \mathrm{~V}$ given every $5 \mathrm{~min}$ using an electrical stimulator. At the end of each electrophysiological experiment, pressure was applied to the electrode (300 mbar, $1 \mathrm{~min}$ ) for marking the recording site with rhodamine $\mathrm{B}$.

Immunohistochemistry. For colocalization studies of the interleukin-1 receptor (IL-1R) with the neuronal marker NeuN, the astrocytic marker glial fibrillary acidic protein (GFAP), and the microglial marker ionized calcium binding adaptor molecule 1 (Iba1), 500- to 600- $\mu$ m-thick slices from the spinal lumbar enlargement were mounted. Slices were fixed for $10 \mathrm{~min}$ in $4 \%$ paraformaldehyde (PFA) dissolved in $0.1 \mathrm{M}$ phosphate buffer $(\mathrm{PB}), \mathrm{pH} 7.3$, at room temperature. Slices were then washed 3 
times for 10 min with PBS. Slices were incubated overnight in PBS containing the following primary antibodies: rabbit anti-IL-1R (1:200; Santa Cruz Biotechnology), together either with mouse anti-NeuN (1:500; Millipore) or mouse anti-GFAP (1:800; ThermoScientific) or goat anti-Iba1 (1:2000; Abcam). Slices were washed again with PBS 3 times for 5 min. The slices were then incubated with the following secondary antibodies diluted in PBS for $1 \mathrm{~h}$ : donkey anti-goat Cy3 and goat anti-mouse $+\mathrm{Cy} 2$ (both 1:200; Jackson ImmunoResearch). Coverslips and Aquatex aqueous mounting agent (Merck) was used to mount slices.

For colocalization studies of TNFR1 with either NeuN or GFAP, naive rats were decapitated and the spinal cord was removed and frozen immediately in isopentane $\left(-80^{\circ} \mathrm{C}\right)$. Transverse sections of $12 \mu \mathrm{m}$ thickness were cut on a freezing microtome. Sections were blocked in PBS stowed with $10 \%$ normal donkey serum (NDS) and $0.1 \%$ Triton X-100 for $30 \mathrm{~min}$. The following primary antibodies were incubated overnight at $4^{\circ} \mathrm{C}$ : rabbit anti-TNFR1 (1:200; Abcam) together either with mouse anti-NeuN (1:500; Millipore) or mouse anti-GFAP (1:800; ThermoScientific). Sections were washed and then incubated with the secondary antibodies for $1 \mathrm{~h}$ at room temperature. Antibodies used were the same as above.

For colocalization studies of TNFR2 with NeuN or GFAP or the microglial marker Ibal, naive rats were perfused first with $20 \mathrm{ml}$ of heparinized $0.9 \%$ saline at room temperature, followed by $140 \mathrm{ml}$ of $4 \%$ PFA at $4^{\circ} \mathrm{C}$. The spinal cord was removed and postfixed for $4 \mathrm{~h}$ in $4 \%$ PFA in $0.1 \mathrm{M} \mathrm{PB}$ at $4^{\circ} \mathrm{C}$. The spinal cord was cryoprotected overnight in $20 \%$ saccharose in $0.1 \mathrm{M} \mathrm{PB}$ at $4^{\circ} \mathrm{C}$ and frozen in isopentane $\left(-80^{\circ} \mathrm{C}\right)$. Transverse sections of $12 \mu \mathrm{m}$ thickness were cut on a freezing microtome. Sections were blocked in PBS stowed with 10\% NDS and 0.1\% Triton $\mathrm{X}-100$ for $30 \mathrm{~min}$. The following primary antibodies were incubated overnight at $4^{\circ} \mathrm{C}$ : rabbit anti-TNFR2 (1:100; Abcam) with either mouse anti-NeuN or mouse anti-GFAP (both as above) or goat anti-Ibal (1: 2000; Abcam). Sections were washed and then incubated with following secondary antibodies for $1 \mathrm{~h}$ at room temperature: donkey anti-rabbit Cy2, together with donkey anti-mouse Cy3 or donkey anti-goat Cy3 (all 1:200; Jackson ImmunoResearch).

Immunohistochemical analysis of the activation of glial cells after HFS was performed as follows. Spinal cord slices from the lumbar enlargement were stimulated by HFS. After stimulation, slices were kept for 30 min or $2 \mathrm{~h}$ in oxygenated recording solution and then used for immunohistochemical analysis. Spinal cord slices were fixed for $4 \mathrm{~h}$ at $4^{\circ} \mathrm{C}$. Slices were cryoprotected in $20 \%$ saccharose dissolved in $0.1 \mathrm{M} \mathrm{PB}$ overnight at $4^{\circ} \mathrm{C}$. Transverse sections of $12 \mu \mathrm{m}$ thickness were cut on a freezing microtome. Sections were blocked in PBS stowed with 10\% NDS and $0.1 \%$ Triton X-100 for $30 \mathrm{~min}$. Primary antibodies were incubated overnight at $4^{\circ} \mathrm{C}$. The antibodies and concentrations were mouse anti-GFAP $(1: 1000$; Thermo Scientific) and goat anti-Ibal (1:2000; Abcam). Section were washed and then incubated with the secondary antibodies for $1 \mathrm{~h}$ at room temperature. Secondary antibodies were donkey anti-mouse Cy2 and donkey anti-goat Cy3 (both 1:200; Jackson ImmunoResearch). Slices were washed again and viewed under a fluorescence microscope equipped with a CCD camera (DP50; Olympus). For p-p38 MAPK immunohistochemistry, naive and HFS-treated animals were transcardially perfused with $20 \mathrm{ml} 0.9 \% \mathrm{NaCl}+10 \mathrm{U} / \mathrm{ml}$ heparin followed by $140 \mathrm{ml} \mathrm{4 \%} \mathrm{PFA} \mathrm{in} 0.1 \mathrm{M} \mathrm{PB}$ (pH 7.3) at RT. The spinal cord was then excised and postfixed for $24 \mathrm{~h}$ at $4^{\circ} \mathrm{C}$. The spinal cord was cryoprotected in $20 \%$ saccharose in $0.1 \mathrm{M} \mathrm{PB}$ ( $\mathrm{pH} 7.3$ ) for $24 \mathrm{~h}$ at $4^{\circ} \mathrm{C}$ and shock-frosted in isopentane at $-80^{\circ} \mathrm{C}$. Transverse sections $(12 \mu \mathrm{m})$ were cryostat-cut from lumbar segments L4-L6 and thaw-mounted onto glass slides. Slides were incubated overnight at $4^{\circ} \mathrm{C}$ with following primary antibodies: rabbit anti-p-p38MAPK (1:50; Cell Signaling Technology) plus goat anti-Ibal (1:1000; Abcam) plus mouse anti-NeuN (1:500; Millipore). Next, secondary antibodies were incubated for $1 \mathrm{~h}$ at room temperature: donkey anti-rabbit + DyLight 488 (Jackson ImmunoResearch) plus donkey anti-goat $+\mathrm{Cy} 3$ (Jackson ImmunoResearch) plus horse anti-mouse + DyLight 649 (Vector). For comparison of p-p38 MAPK positive cells between naïve and HFS-treated animals, p-p38 MAPK positive structures were counted in lamina I.

Western blot analysis. For Western blot analysis, the lumbar spinal cord of 24 - to 26 -d-old rats was removed and incubated with IL-1 $\beta$ (20 ng/ $\mathrm{ml}), \mathrm{TNF} \alpha(20 \mathrm{ng} / \mathrm{ml})$, or vehicle for $20 \mathrm{~min}$ in oxygenated recording solution. After incubation, the dorsal horn from lumbar segments 4-6 was removed and frozen in liquid nitrogen. The samples were homogenized in $700 \mu$ l of working buffer ( $10 \mathrm{~mm}$ Tris, $300 \mathrm{~mm}$ sucrose, $1 \mathrm{~mm}$ EDTA, $\mathrm{pH}$ 7.5) that contained protease and phosphatase inhibitors using an ultrasound sonicator. Samples were centrifuged for $5 \mathrm{~min}$ at $7500 \mathrm{rpm}$ at $4^{\circ} \mathrm{C}$. The supernatant was again centrifuged for $1 \mathrm{~h}$ at 13,000 rpm at $4^{\circ} \mathrm{C}$. The supernatant containing proteins from the cytosol was collected and the membrane pellet was dissolved in distilled water. Protein concentrations were measured. For Western blot analysis, probes were diluted 1:1 in a mixture of NuPAGE LDS sample buffer and NuPAGE Sample Reducing Agent (both Invitrogen) and heated for $10 \mathrm{~min}$ at $70^{\circ} \mathrm{C}$. Equal amounts of protein were size fractioned by SDS-PAGE ( $8 \%$ gel) using the Bio-Rad Mini-Protean 3 Cell System and transferred to a nitrocellulose membrane (Protran; Whatman). The blot was placed in blocking buffer consisting of dry milk powder and Tween 80 (Sigma) in PBS for $1 \mathrm{~h}$ and then incubated overnight at $4^{\circ} \mathrm{C}$ with the primary rabbit polyclonal antibodies against GluR1 (1:500; Millipore) and phosphoNR1-Ser896 (1:2000; Millipore) The expression of $\beta$-actin (monoclonal anti- $\beta$-actin, 1:700, Sigma) was tested as an internal loading control. All antibodies were diluted with blocking buffer. The blots were washed and then incubated with peroxidase-conjugated anti-rabbit IgG and peroxidase-conjugated anti-mouse IgG (both Jackson ImmunoResearch) for $2 \mathrm{~h}$ at room temperature. After washing the blots again, the bands were visualized by the Immobilon Western Chemiluminescent HRP substrate (Millipore) and detected by the Bio-Rad Fluor-S MultiImager. Densitometric quantification of the bands was performed with Bio-Rad Quantity One software.

Release of cytokines in response to $I L-1 \beta$ and TNF- $\alpha$. Spinal cord dorsal horn slices were incubated in $5 \mathrm{ml}$ of IL- $1 \beta(20 \mathrm{ng} / \mathrm{ml})$ or TNF- $\alpha(20$ $\mathrm{ng} / \mathrm{ml}$ ) for $20 \mathrm{~min}$. Control slices were kept in $5 \mathrm{ml}$ of recording solution for $20 \mathrm{~min}$. The $5 \mathrm{ml}$ fractions were collected to measure cytokine levels using a rat cytokine array (RayBiotech).

Behavior. On two consecutive days before the experiment, animals were put in plastic boxes and habituated to the testing. Thermal hyperalgesia was assessed by measuring paw withdrawal latencies using Hargreaves' radiant heat test. Under isoflurane anesthesia, fluorocitrate (1 nmol dissolved in $10 \mu \mathrm{l}$ of $0.9 \%$ saline) was injected into the lumbar region (between the L5 and L6 vertebrae) of the spine $2 \mathrm{~h}$ before the injection of IL- $1 \beta$ or TNF- $\alpha$ ( 20 ng dissolved in $10 \mu$ l of $0.9 \%$ saline). The single injection of IL- $1 \beta$, TNF- $\alpha$, or saline alone served as a control.

Data analysis and statistical analysis. Data were analyzed offline using Clampfit 10 (Molecular Devices) and SigmaPlot 11 (Systat). Values are presented as means \pm SEM. For the quantification of synaptic strength, the peak amplitude of the evoked EPSC was measured. The mean amplitudes of four EPSCs (in some cases, six) before the conditioning stimuli served as a control. LTP was defined as a significant increase in the EPSC amplitudes after the conditioning stimuli remaining over $30 \mathrm{~min}$. Data were tested for normality (Kolmogorov-Smirnov test) first. One-way repeated-measures (RM) ANOVA with Bonferroni adjustment or the nonparametric RM ANOVA on ranks with Dunnett's adjustment was performed to test for potentiation and drug effects statistically. Comparisons between groups were performed using a $t$ test. For in vivo experiments, the area under the curve of C-fiber-evoked field potentials was determined offline using Clampfit 10. The mean area under the curve of at least six consecutive field potentials before HFS or drug application served as a control. Responses were normalized for each rat. Data were tested for normality and then a one-way RM ANOVA was performed to test the effects of HFS and drug application. ANOVA was corrected by the Bonferroni adjustment. For immunohistochemical experiments, a one-way ANOVA was used for the determination of significant difference. For release studies, $t$ tests were used. $p<0.05$ was considered statistically significant. Values are expressed as mean \pm SEM. Behavioral data were analyzed using a two-way RM ANOVA comparing treatments and time points.

Drugs. The following drugs were purchased from Sigma-Aldrich: bicuculline methiodide $(10 \mu \mathrm{M})$, minocycline dihydrochloride (100 and 20 $\mu \mathrm{M})$, sodium-fluorocitrate $(5 \mathrm{~mm})$, and strychnine $(4 \mu \mathrm{M})$. CNQX (10 $\mu \mathrm{M})$ and D-AP5 $(50 \mu \mathrm{M})$ were from Ascent Scientific. Rat recombinant 

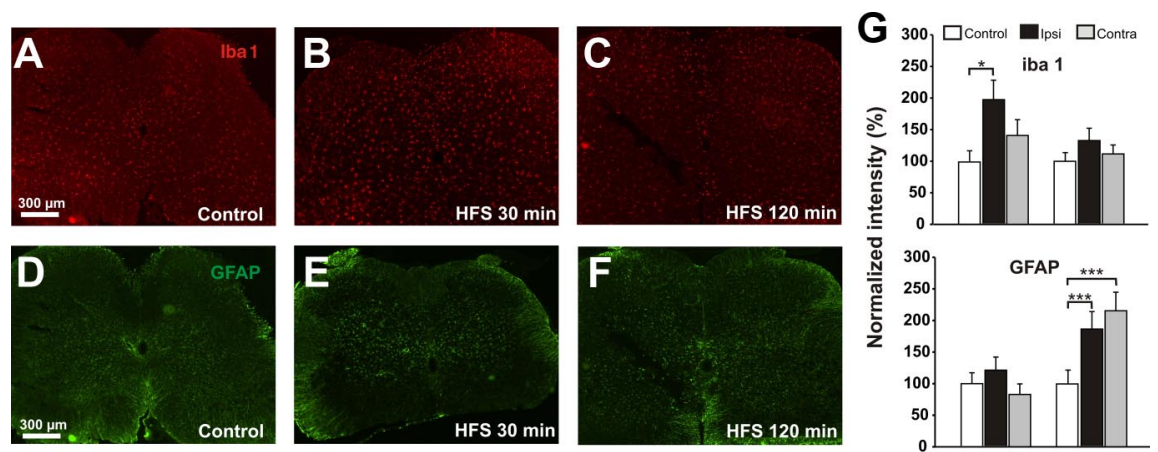

Figure 1. HFS activates microglia and astrocytes. Representative experiments show the changes in microglial $(A-C)$ and astrocytic $(D-F)$ specific markers after HFS of primary afferent fibers. $A, D$, Immunoreactivity for the microglia-specific marker Iba1 $(\boldsymbol{A}$, $n=15$ slices) and the astrocyte-specific marker $\operatorname{GFAP}(\boldsymbol{D}, n=16$ slices) in untreated slices. $\boldsymbol{B}, 30$ min after HFS, Iba1 immunofluorescence is increased on the ipsilateral site (right) but not contralaterally to HFS ( $n=14$ slices). $C, 120$ min after HFS, Iba1 levels are back to control again ( $n=14$ slices). $\boldsymbol{E}$, Thirty minutes after HFS, GFAP immunoreactivity is unchanged compared with control ( $n=16$ slices). $\boldsymbol{F}$, Two hours after HFS of primary afferents, GFAP shows increased immunoreactivity on the ipsilateral (right) and contralateral (left) side ( $n=16$ slices). G, Quantification of Iba1 and GFAP intensity 30 and 120 min after HFS. ${ }^{*} p<0.05$; ${ }^{* *} p<$ 0.001 ; one-way ANOVA.

IL-1 $\beta$ (20 ng/ml, $100 \mathrm{ng} / \mathrm{ml}$ in vivo) and TNF- $\alpha(20 \mathrm{ng} / \mathrm{ml}, 100 \mathrm{ng} / \mathrm{ml}$ in vivo) and a soluble TNF- $\alpha$ receptor (sTNFR; TNF RI/1A, $0.5 \mu \mathrm{g} / \mathrm{ml}, 1$ $\mu \mathrm{g} / \mathrm{ml}$ in vivo) were from R\&D Systems. IL-1 receptor antagonist (IL-1ra; $40 \mathrm{ng} / \mathrm{ml}, 400 \mathrm{ng} / 10 \mu \mathrm{l}$ in vivo) was from AbD Serotec.

\section{Results}

Role of spinal glial cells for LTP induction at C-fiber synapses in spinal cord lamina I

Microglia and astrocytes become activated by HFS

We first investigated whether microglia and astrocytes were activated by conditioning HFS, which induces LTP at C-fiber synapses. The microglia-specific marker Ibal was significantly upregulated $30 \mathrm{~min}$ after HFS in the ipsilateral but not in the contralateral dorsal horn, including lamina I, as assessed by immunohistochemistry (Fig. 1A,B,G, increase to $197 \pm 30 \%$ of control values, $p<0.05$, one-way ANOVA). The Ibal immunoreactivity returned to control values $120 \mathrm{~min}$ after HFS (Fig. $1 C, G, p>0.05$, one-way ANOVA). Astrocytes were also activated by HFS, but with a delayed and prolonged time course as judged by the specific marker for activated astrocytes, GFAP, which was unchanged $30 \mathrm{~min}$ after conditioning HFS (Fig. 1D,E,G, $121 \pm$ $20 \%$ of control, $p>0.05$, one-way ANOVA). At 120 min after HFS, a time point when the microglial marker Ibal had returned to baseline, GFAP was significantly upregulated in both the ipsilateral and contralateral dorsal horn lamina I (Fig. $1 F, G, 187 \pm$ $27 \%$ ipsilateral and $216 \pm 28 \%$ contralateral of control, $p<$ 0.001 , one-way ANOVA).

\section{Astrocytes respond rapidly to HFS with an intracellular}

\section{$\mathrm{Ca}^{2+}$ increase}

The immunohistochemical analysis revealed responses of astrocytes to HFS that were delayed by $>30 \mathrm{~min}$. This could indicate that astrocytes generally respond slowly to HFS of dorsal root afferents or that the marker GFAP cannot detect any faster responses. To differentiate between these possibilities, we investigated whether astrocytes react more quickly to HFS with a rise in the intracellular $\mathrm{Ca}^{2+}$ concentration. We injected the $\mathrm{Ca}^{2+}$-sensitive dye Oregon Green BAPTA 1-AM by pressure into spinal cord slices. $\mathrm{Ca}^{2+}$ responses and kinetics of astrocytes in the spinal dorsal horn were studied in seven slices that were incubated with the astrocyte-specific marker SR101. All SR101-positive astrocytes $(n=16$; Fig. $2 A)$ reacted with a typical delay of $\sim 2$ s to electrical stimulation, which was significantly slower than the corresponding $\mathrm{Ca}^{2+}$ rises in neurons (Fig. $2 B$ ). In the ensuing experiments, astrocytic $\mathrm{Ca}^{2+}$ responses could thus securely be differentiated from neuronal $\mathrm{Ca}^{2+}$ responses by the typical 2 s delay and by their slower decay kinetics (see below). To ensure good input from dorsal root afferents, only those slices in which at least 10 neurons responded with a clear $\mathrm{Ca}^{2+}$ increase to HFS were considered for further analysis. In all slices that fulfilled this criterion, astrocytes reacted to primary afferent HFS with a $\mathrm{Ca}^{2+}$ increase. Neurons showed a mean $\mathrm{Ca}^{2+}$ rise of $85 \pm$ $5 \%\left(\Delta F / F_{0}, n=85\right.$ neurons $)$ with a delay that was below the temporal resolution of the imaging protocol. Astrocytes reacted with a mean delay of $2.2 \pm 0.08 \mathrm{~s}$ $(n=16$ cells $)$ and a mean peak increase in $\mathrm{Ca}^{2+}$ concentration by $94 \pm 7 \%(n=$ 47 cells). The mean decay kinetics (from $90 \%$ to $10 \%$ ) of astrocytic $\mathrm{Ca}^{2+}$ responses were significantly slower (14.3 \pm $1.8 \mathrm{~s})$ than those of neurons $(2.5 \pm 0.15 \mathrm{~s}$; Fig. $2 C, n=47$ cells, $p<0.001, t$ test $)$.

\section{p-p38 MAPK does not increase after HFS}

We also investigated whether microglia responded at an earlier time point than was indicated by changes in Ibal immunoreactivity. Phosphorylation of p38 mitogen-activated protein kinase (p-p38 MAPK) is increased in microglia after peripheral nerve injury or inflammation and can be considered a marker for rapid microglial activation (Clark et al., 2006; Clark et al., 2009). An increase in p-p38 MAPK levels can be detected as early as 5 min and peaks at $15 \mathrm{~min}$ after an intraplantar injection of formalin. It is still slightly increased after $60 \mathrm{~min}$ (Svensson et al., 2003; Svensson et al., 2005). In lamina I, p-p38 MAPK immunoreactivity was not significantly increased 15 min after HFS, but rather decreased on the ipsilateral side compared with naive animals (naive: $13 \pm$ 2 cells, 15 min HFS: $7 \pm 1$ cells; $p<0.05$, $t$ test, data not shown). We could also not detect any changes in p-p38-MAPK-positive cells in lamina I $3 \mathrm{~h}$ after HFS compared with naive animals $(3 \mathrm{~h}$ HFS: $13 \pm 1$ cells; $p>0.05, t$ test). Approximately $85 \%$ of $\mathrm{p}$-p 38 MAPK-positive cells also showed staining for the microglial marker Iba1, and all other cells were positive for the neuronal marker NeuN. These results suggest that HFS, which activates microglia, does not change p-p38 MAPK immunoreactivity.

Blockade of glial cell function abolishes induction of LTP by HFS We next investigated whether spinal glial cells are required for the induction of LTP at synapses between primary afferent $\mathrm{C}$-fibers and lamina I neurons in vitro. We induced spinal LTP by HFS (Fig. $3 A$, B, Ikeda et al., 2003; Ikeda et al., 2006). In 13 of 19 neurons, synaptic transmission was significantly enhanced to $246 \pm 36 \%$ of control levels 30 min after conditioning stimulation ( $n=13$ neurons, $p<0.001$, one-way RM ANOVA). In the other six neurons, HFS had no effect on synaptic strength ( $p>0.05$, one-way RM ANOVA). To determine whether microglia and astrocytes are necessary for the induction of spinal LTP, we applied the glial cell inhibitor fluorocitrate $(0.01 \mathrm{~mm})$ to the spinal cord. Fluorocitrate had 
A
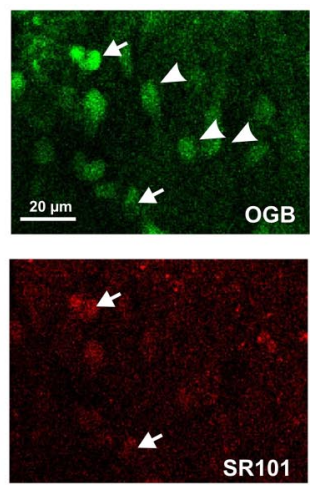

B

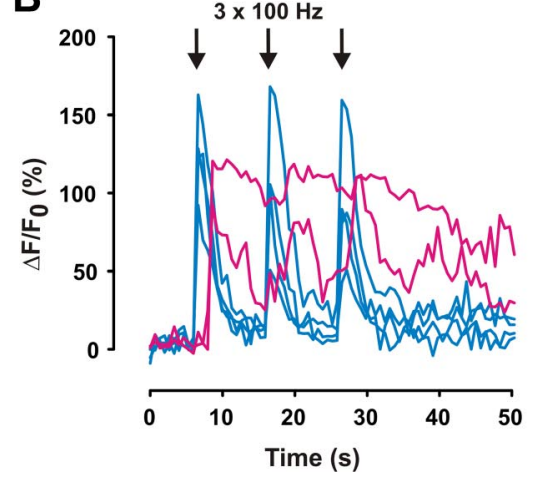

C

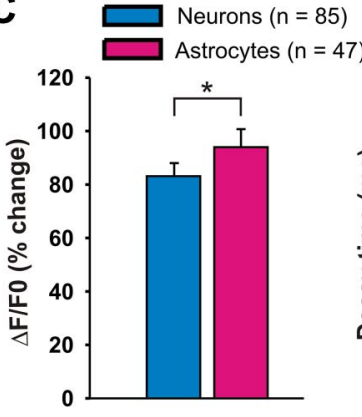

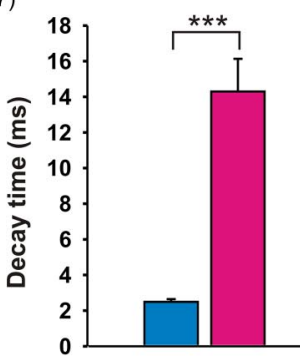

Figure 2. Astrocytes respond to HFS with an intracellular $\mathrm{Ca}^{2+}$ rise. $\boldsymbol{A}$, Example of a spinal cord slice loaded with the $\mathrm{Ca}^{2+}$-sensitive dye 0 regon Green BAPTA 1-AM (0GB, green) and the astrocytic marker SR101 (red). Neurons are depicted with an arrowhead, astrocytes with an arrow. $\boldsymbol{B}$, Time course of the HFS-mediated $\mathrm{Ca}^{2+}$ response of the three neurons (blue) and two astrocytes (purple) depicted in $\boldsymbol{A}$. The $\mathrm{Ca}^{2+}$ rise in neurons is followed by a prolonged $\mathrm{Ca}^{2+}$ increase in astrocytes. $\boldsymbol{C}$, Description of differences in $\mathrm{Ca}^{2+}$ kinetics between neurons and astrocytes. The increase in fluorescence and decay time was calculated between all neurons and all astrocytes recorded. ${ }^{* * *} p<0.001$.

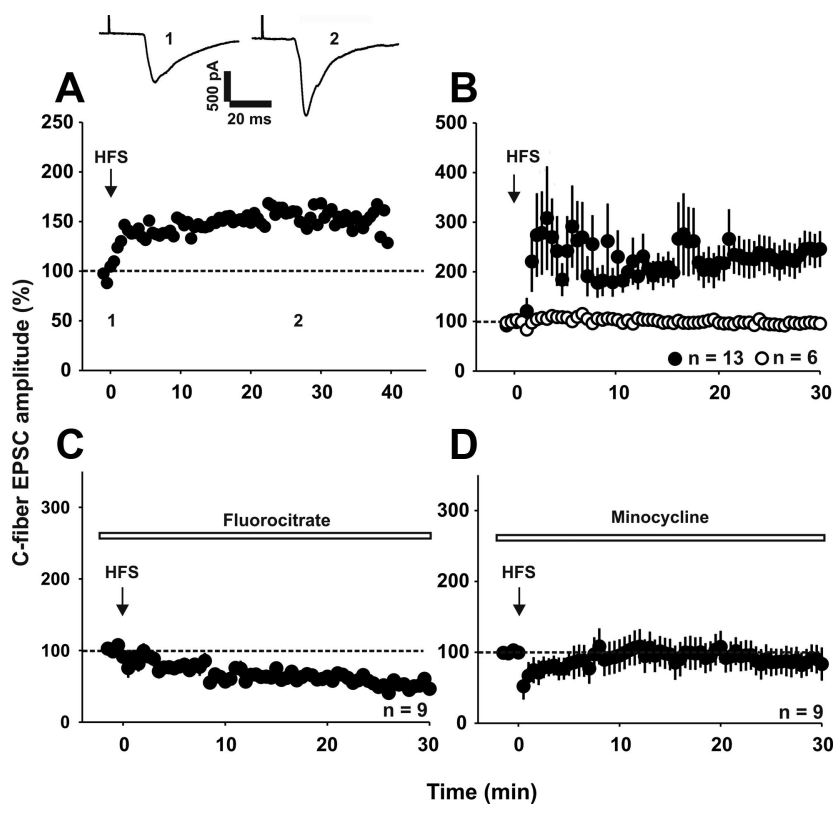

Figure 3. Spinal glia are necessary for LTP induction in vitro. Recordings were performed in lamina I neurons of the spinal cord dorsal horn. $A$, Example of HFS-induced LTP in one spinal lamina I neuron. Amplitudes of individual EPSCs were normalized to pretreatment values (dotted line) and plotted against time. The time point at which HFS was applied is depicted with an arrow. Insets show individual EPSC traces recorded at the indicated time points. $B$, Average time course of EPSC amplitude (mean \pm SEM) of 19 lamina I neurons in which HFS was applied. In 13 of 19 neurons tested, HFS induces a significant increase in EPSC amplitude 30 min after conditioning stimulation ( $p<0.001, n=13$ neurons, one-way RM ANOVA). C, Application of fluorocitrate $(0.01 \mathrm{~mm})$ to spinal cord slices inhibits LTP induction by HFS ( $n=9$ neurons; $p<$ 0.05 compared with control conditions; Fisher's exact test). D, Averaged time course of nine neurons in which minocycline prevents the induction of LTP after HFS. Slices were incubated with minocycline $(100 \mu \mathrm{M})$ for $1 \mathrm{~h}$ before the experiments and minocycline $(20 \mu \mathrm{M})$ was bath applied during the entire experiment. C-fiber-evoked EPSC amplitudes stay at control values (dotted line) after HFS (30 min after HFS, $p>0.05$, one-way RM ANOVA).

no effect on baseline synaptic transmission ( $98 \pm 17 \%$ of control within $30 \mathrm{~min}, n=11$ neurons, $p>0.05$, one-way RM ANOVA, data not shown), but abolished induction of LTP by HFS (Fig. $3 C, 53 \pm 4 \%$ of control $30 \mathrm{~min}$ after HFS, $n=9$ neurons, $p<0.05$, one-way RM ANOVA; $p<0.05$ when compared with control conditions, Fisher's exact test). We also used minocycline $(100 \mu \mathrm{M})$ as a pharmacological tool to block cytokine release (Kremlev et al., 2004; Henry et al.,
2008). Minocycline had no effect on baseline synaptic transmission (92 $\pm 19 \%$ of control within $30 \mathrm{~min}, n=7$ neurons, $p>0.05$, one-way RM ANOVA, data not shown), but abolished induction of LTP by HFS (Fig. 3D, $90 \pm 20 \%$ of control 30 min after HFS, $n=9$ neurons, $p>0.05$, one-way RM ANOVA).

\section{The role of IL-1 $\beta$ and TNF- $\alpha$ for LTP induction at C-fiber} synapses in lamina I

Redundancy of IL-1 $\beta$ and TNF- $\alpha$ signaling for LTP induction We investigated whether the blockade of IL- $1 \beta$ and/or TNF- $\alpha$ signaling had any effect on the induction of LTP by HFS. We applied IL-1ra and/or sTNFR before conditioning HFS. Neither IL-1ra nor sTNFR1 alone had any significant influence on the induction of LTP at C-fiber synapses in spinal lamina I neurons. In the presence of IL-1ra, LTP was induced in 8 of 14 neurons (Fig. $4 A$ ), which is not statistically different from control conditions (Fig. $3 B, p>0.05$, Fisher's exact test). In the presence of sTNFR, LTP was induced in 8 of 13 neurons tested (Fig. $4 B, p>$ 0.05 , Fisher's exact test). Likewise, the magnitude of spinal LTP 30 min after HFS did not differ between untreated slices $(n=13$ neurons, $246 \pm 36 \%$ of control) and slices incubated with IL-1ra ( $n=8$ neurons, $161 \pm 21 \%$ of control) or sTNFR1 $(n=8$ neurons, $150 \pm 6 \%$ of control, $p>0.05$, one-way ANOVA). However, when slices were incubated with both IL-1ra and sTNFR, LTP induction by HFS was abolished (Fig. $4 C, n=9$ neurons, $p<$ 0.001, Fisher's exact test), suggesting that LTP induction by HFS required activity of at least one cytokine, IL- $1 \beta$ or TNF- $\alpha$.

\section{TNF- $\alpha$ and IL-1 $\beta$ induce LTP at C-fiber synapses with lamina}

I neurons

We next investigated whether IL- $1 \beta$ and TNF- $\alpha$ are not only required but also sufficient for the induction of LTP. Under control conditions, C-fiber-evoked EPSC amplitudes stayed stable at $96 \pm$ $2 \%$ of baseline over a recording period of $30 \mathrm{~min}$ (Fig. $5 \mathrm{~A}, n=15$ neurons, $p>0.05$, one-way RM ANOVA). Bath application of TNF- $\alpha$ increased strength at C-fiber synapses in 6 of 15 neurons ( $p<0.05$, Fisher's exact test) to $160 \pm 9 \%$ of baseline (Fig. $5 B, p<$ 0.001 , one-way RM ANOVA). Likewise, bath application of IL-1 $\beta$ $(20 \mathrm{ng} / \mathrm{ml})$ significantly potentiated synaptic strength in C-fibers in 11 of 15 neurons tested ( $p<0.001$, Fisher's exact test) up to $137 \pm$ $5 \%$ of baseline (Fig. $5 C, p<0.001$, one-way RM ANOVA). 

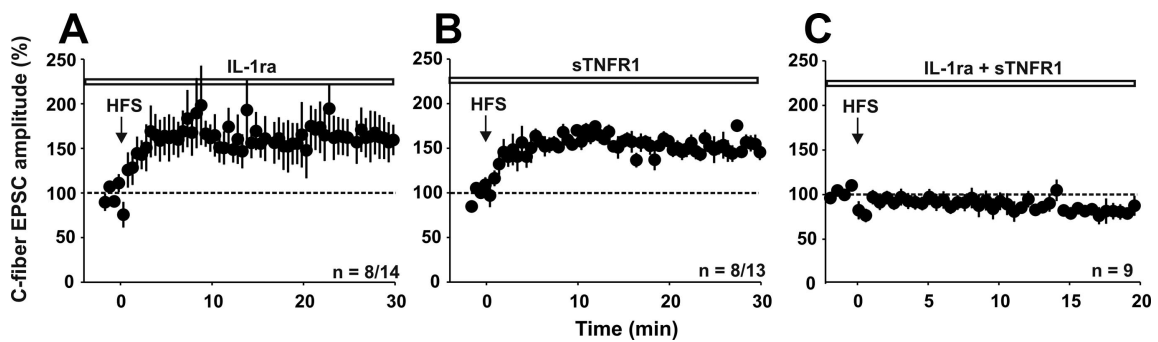

Figure 4. IL-1 $\beta$ and TNF- $\alpha$ are necessary for LTP induction in vitro. Recordings were performed in lamina I neurons of the spinal cord dorsal horn. A, Bath application of IL-1ra $(40 \mathrm{ng} / \mathrm{ml})$ does not prevent LTP induction in 8 of 14 neurons tested $(p>0.05$ compared with untreated slices, Fisher's exact test). $\boldsymbol{B}$, A soluble TNF receptor (sTNFR1, $0.5 \mu \mathrm{g} / \mathrm{ml}$ ) also does not inhibit LTP induction by HFS in 8 of 13 neurons recorded ( $p>0.05$ compared with untreated slices, Fisher's exact test). C, Application of both IL-1ra and sTNFR1 prevents LTP induction in all neurons tested $(n=9, p<0.05$ compared with untreated slices, Fisher's exact test).
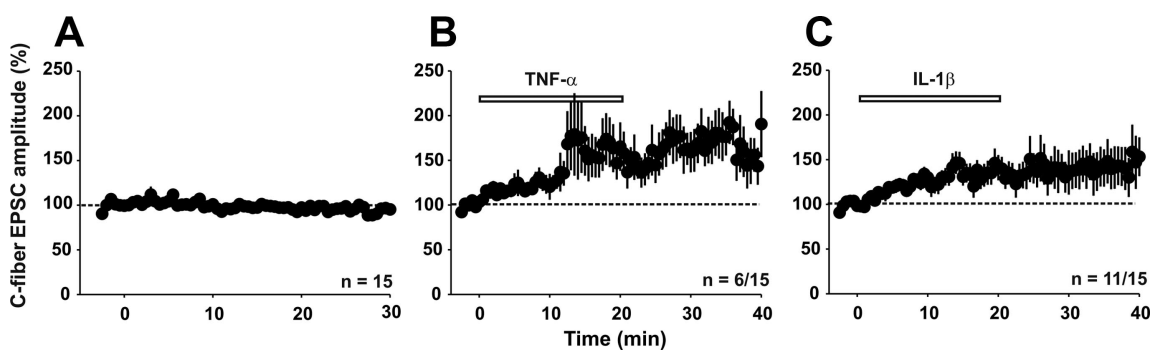

Figure 5. Potentiation of synaptic transmission by TNF- $\alpha$ and IL-1 $\beta$. Patch-clamp recordings of spinal lamina I neurons show an increase in evoked excitatory synaptic transmission after bath application of the pro-inflammatory cytokines IL- $1 \beta$ and TNF- $\alpha$. C-fiber-evoked EPSC amplitude (\% control) is plotted against time ( $\mathrm{min})$. $A$, In 15 neurons tested, $(-$-fiber-evoked EPSC amplitude stays constant over a recording period of $30 \mathrm{~min}$ ( $p>0.05$, one-way RM ANOVA). B, Bath application of TNF- $\alpha(20 \mathrm{ng} / \mathrm{ml}, 20 \mathrm{~min})$ significantly augments C-fiber-evoked EPSC amplitude in 6 of 15 neurons tested $(p<0.05$ compared with control, Fisher's exact test). C, Application of IL-1 $\beta$ (20 ng/ml) for 20 min increases synaptic transmission in 11 of 15 neurons tested $(p<0.001$, compared with control, Fisher's exact test).
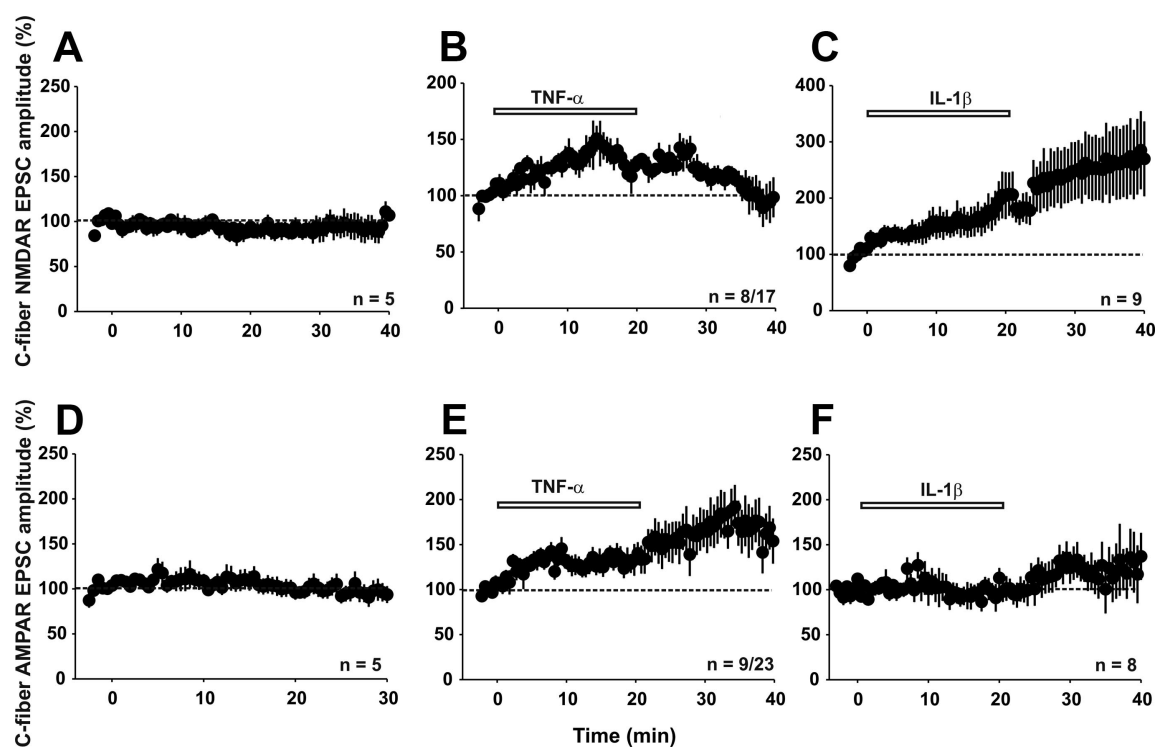

Figure 6. Effects of IL-1 $\beta$ and TNF- $\alpha$ on synaptic transmission mediated by NMDA or AMPARs. Means \pm SEM of NMDARevoked $(\boldsymbol{A}-\boldsymbol{C})$ or AMPAR-evoked $(\boldsymbol{D}-\boldsymbol{F})$ EPSC amplitudes were calculated and plotted against time (min). $\boldsymbol{A}$, NMDAR-mediated currents do not change significantly over a recording period of $40 \min (n=5, p>0.05$, one-way RM ANOVA). $\boldsymbol{B}$, Bath application of TNF- $\alpha$ increases synaptic transmission mediated by NMDARs in a subset ( 8 of 17) of lamina I neurons ( $p<0.001$, one-way RM ANOVA). C, In nine neurons recorded, IL-1 $\beta$ significantly potentiates NMDAR-mediated EPSC amplitude ( $p<0.001,20$ min after wash-in of IL-1 $\beta$ compared with baseline, one-way RM ANOVA). D, AMPAR-mediated currents stayed stable over a recording period of $30 \mathrm{~min}(n=5$ neurons, $p>0.05$, one-way RM ANOVA). $\boldsymbol{E}$, TNF- $\alpha(20 \mathrm{ng} / \mathrm{ml})$ significantly enhances AMPAR-mediated currents in nine of 23 neurons tested ( $p<0.05,20 \mathrm{~min}$ after TNF- $\alpha$ application compared with baseline). $\boldsymbol{F}$, In eight neurons tested, IL-1 $\beta$ ( $20 \mathrm{ng} / \mathrm{ml}$ ) has no significant effect on AMPAR-mediated currents ( $p>0.05,20 \mathrm{~min}$ after IL-1 $\beta$ compared with pre-observation).
Effects of TNF- $\alpha$ on NMDAR- and AMPAR-mediated synaptic transmission At C-fiber synapses, fast transmission by glutamate largely consists of AMPARand NMDAR-mediated currents. Therefore, we assessed the effects of TNF- $\alpha$ and IL- $1 \beta$ on AMPAR- and NMDARmediated synaptic transmission. We evaluated NMDAR-mediated currents in the presence of CNQX $(10 \mu \mathrm{M})$, bicuculline $(10 \mu \mathrm{M})$, and strychnine $(4 \mu \mathrm{M})$ to selectively block the AMPA, GABA ${ }_{\mathrm{A}}$, and glycine receptors, respectively. NMDARmediated synaptic currents were recorded at a holding potential of $-30 \mathrm{mV}$. Under control conditions, NMDAR-mediated currents were stable throughout the recording period of $40 \mathrm{~min}$ (Fig. $6 A, 101 \pm$ $5 \%$ of control, $n=5$ neurons, $p>0.05$, one-way RM ANOVA). Bath application of TNF- $\alpha$ for 20 min enhanced synaptic NMDAR-mediated currents. In 8 of 17 neurons tested, TNF- $\alpha$ increased the mean NMDAR-mediated currents reversibly to $136 \pm 2 \%$ of control (Fig. $6 B, p<$ 0.001 , one-way RM ANOVA; $95 \pm 2 \%$ of control at 20 min after washout, $p>0.05$ ). In 4 of 17 neurons, TNF- $\alpha$ decreased synaptic transmission by NMDARs to $74 \pm$ $2 \%$ of control (data not shown, $p<0.001$, one-way RM ANOVA). Upon washout of TNF- $\alpha$, responses were potentiated to $130 \pm 1 \%$ of control in these four neurons $(p<0.001$, one-way RM ANOVA). In the remaining five neurons, TNF- $\alpha$ had no effect (data not shown). We next isolated AMPAR-mediated synaptic currents pharmacologically by application of bicuculline, strychnine, and the NMDAR blocker D-AP5 $(50 \mu \mathrm{M})$. In the absence of exogenous TNF- $\alpha$, AMPAR-mediated currents remained stable over a recording period of 30 min (Fig. $6 D, 95 \pm 10 \%$ of control, $n=5$ neurons, $p>0.05$, one-way RM ANOVA). TNF- $\alpha$ added to the bath solution enhanced synaptic AMPAR-mediated currents in 9 of 23 neurons to $140 \pm 12 \%$ of baseline (Fig. $6 E, p<0.05$, one-way RM ANOVA).

AMPAR trafficking may lead to enhanced glutamatergic transmission, which may contribute to the development of hyperalgesia after a painful stimulus (Galan et al., 2004). TNF- $\alpha$ could be involved in this because it increases membrane-bound AMPARs, at least in hippocampal neurons (Beattie et al., 2002). Therefore, we investigated whether exposure of spinal dorsal horn neurons to TNF- $\alpha$ results in a delivery of the GluR1 AMPAR subunit to the cell membrane. The cytoplasmic fraction of GluR1 was significantly reduced in spinal cords treated with TNF- $\alpha$ (Fig. $7 A ; n=15, p<$ 0.01 , $t$ test). However, the fraction of 

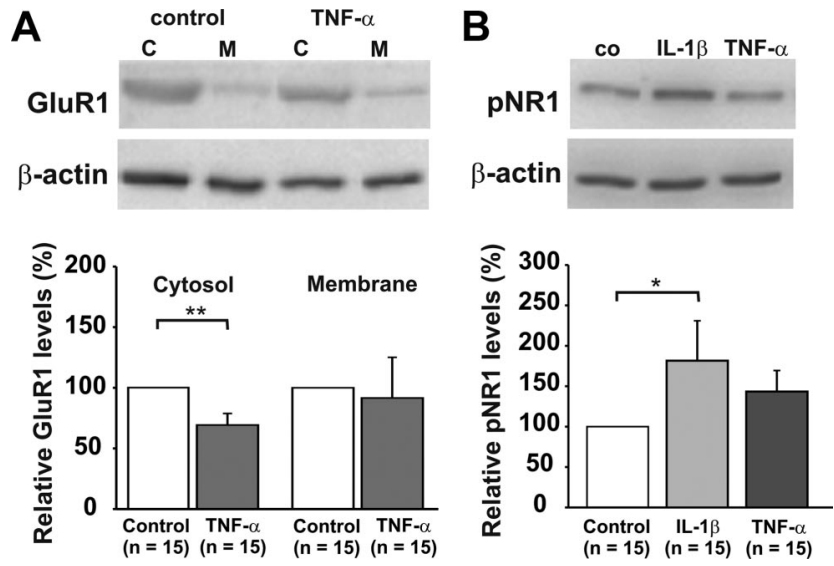

Figure 7. Effects of TNF- $\alpha$ on AMPAR trafficking and IL-1 $\beta$ on NMDAR phosphorylation (pNR1). Representative immunoblots are shown on top, and mean relative protein levels are displayed in the bar graphs. Spinal cords were obtained from 20- to 23-d-old rats. Spinal cords were incubated with TNF- $\alpha(20 \mathrm{ng} / \mathrm{ml})$ or IL-1 $\beta(20 \mathrm{ng} / \mathrm{ml})$ for $20 \mathrm{~min}$. Data are displayed as mean \pm SEM. $A$, TNF- $\alpha$ decreased cytosolic GluR1 significantly ( $n=15$ spinal cords, $p<0.01$, $t$ test) but had no effect on the membrane fraction of GluR1 ( $n=15$ spinal cords, $p>0.05, t$ test). $\boldsymbol{B}$, Western blot analysis of spinal cords treated with IL- $1 \beta$ and TNF- $\alpha$ revealed that IL- $1 \beta$ significantly increased NMDAR phosphorylation ( $n=15$ spinal cords, $p<0.05, t$ test), whereas TNF- $\alpha$ did not significantly alter NMDAR phosphorylation ( $n=15$ spinal cords, $p>0.05, t$ test).

membrane-bound GluR1 was not significantly different between control ( $n=15$ spinal cords) and TNF- $\alpha$-treated spinal cords $(n=$ $15, p>0.05, t$ test). Therefore, from the present data, we cannot conclude that a potentiation of AMPAR-mediated currents by TNF- $\alpha$ is due to an increase in membrane-bound, GluR1containing AMPARs in the superficial spinal dorsal horn.

\section{$I L-1 \beta$ increases NMDAR- but not AMPAR-mediated synaptic transmission}

We also investigated the effect of IL- $1 \beta$ on AMPAR-mediated currents at C-fiber synapses in spinal lamina I neurons. IL- $1 \beta$ had no significant effect on AMPAR-mediated currents in any of the eight neurons tested. After $20 \mathrm{~min}$ of application, amplitudes stayed at $97 \pm 11 \%$ of baseline (Fig. $6 F, p>0.05$, one-way RM ANOVA).

We next investigated whether IL- $1 \beta$ had any effect on NMDAR-mediated currents. Superfusion with IL- $1 \beta$ for 20 min significantly increased mean NMDAR-mediated currents to $189 \pm 6 \%$ of control in all nine neurons tested (Fig. $6 C, p<0.001$, one-way RM ANOVA). Twenty minutes after IL- $1 \beta$ washout, NMDAR-mediated currents were further potentiated to $278 \pm$ $4 \%$ of control ( $p<0.001$, one-way RM ANOVA).

We next investigated whether the increase in NMDARmediated currents was associated with NMDAR phosphorylation. Western blot analysis revealed that incubation of slices with IL- $1 \beta$ for 20 min led to a significant increase in NMDAR phosphorylation at Ser896 compared with control $(n=15$ spinal cords, $p<0.05, t$ test). In contrast, TNF- $\alpha$ had no significant effect on NR1 phosphorylation at Ser896 (Fig. $7 B, n=15$ spinal cords, $p>0.05, t$ test).

Cytokine receptors are expressed by neurons and glial cells in superficial dorsal horn

It is presently unknown which cells in spinal dorsal horn lamina I express the TNF- $\alpha$ and IL-1 receptors. There exist two different receptors for TNF- $\alpha$ (TNFR1 and TNFR2), which mediate different cellular responses via distinct signaling
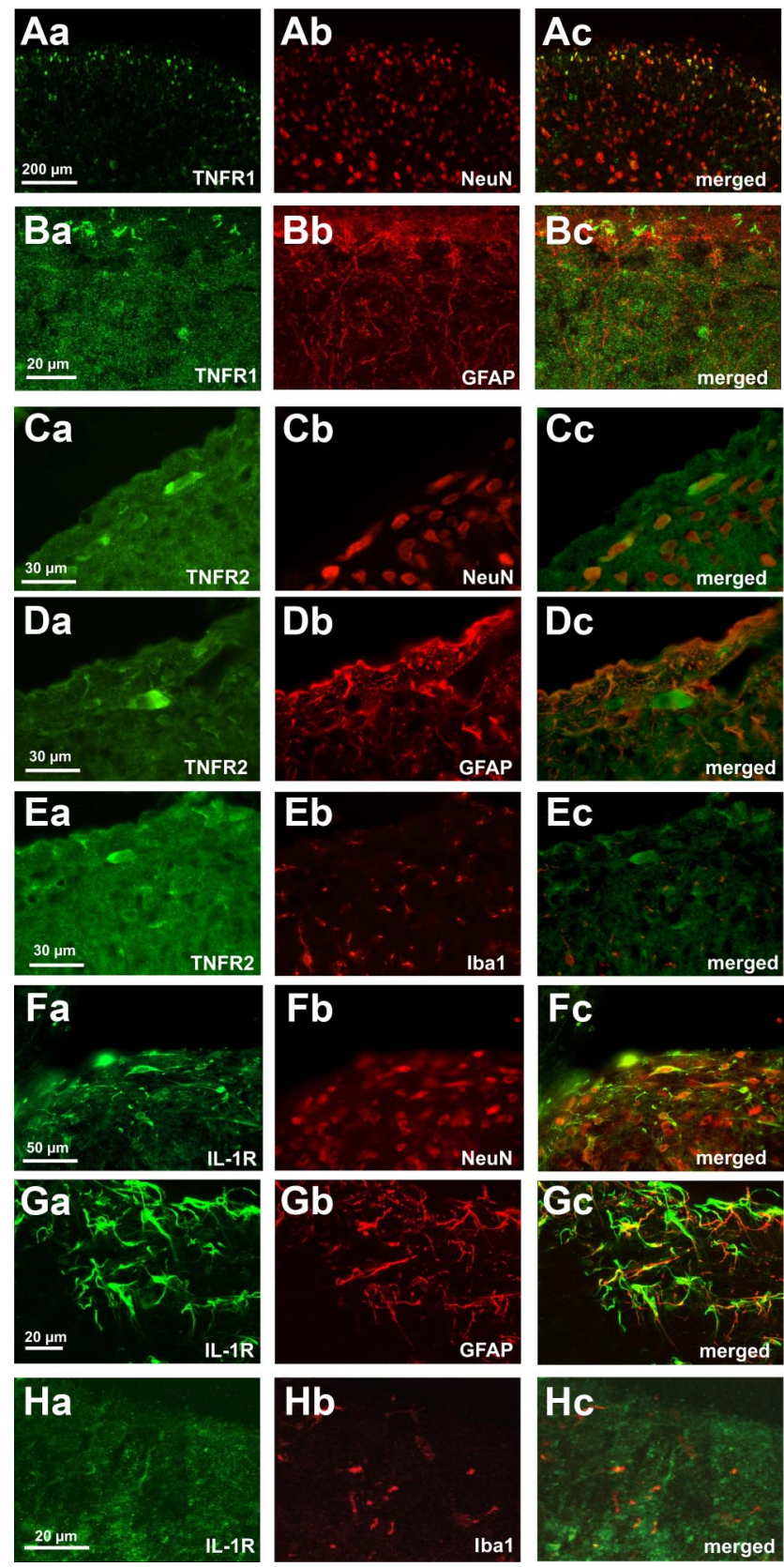

Figure 8. Receptors for the pro-inflammatory cytokines TNF- $\alpha$ and IL-1 $\beta$ are expressed by lamina I neurons and glial cells. Double immunostaining shows colocalization of TNFR1 ( $A a, B a$, green) and TNFR2 ( $C a, D a, E a$, green) and ILIR ( $F a, G a, H a$, green) with the neuronal marker NeuN $(A b, C b, F b$, red), the astrocytic marker GFAP $(B b, D b, G b$, red), and the microglial marker Iba1 $(E b, H b$, red) in spinal cord lamina I. Overlays reveal that lamina I neurons express TNFR1, TNFR2, and IL-1R. TNFR1 and IL-1R are also expressed by GFAPpositive cells in the spinal dorsal horn. There is weak costaining for the individual receptors and the microglial marker Iba1.

pathways. Our immunohistochemical analysis revealed that a subgroup of lamina I neurons expressed TNFR1 and TNFR2 (Fig. $8 A, C$ ). A subset of lamina I neurons also expressed the IL-1R (Fig. $8 F$ ). Costaining with the astrocyte-specific marker GFAP (Fig. $8 B b, D b, G b$ ) revealed that TNFR1 (Fig. $8 B a$ ), TNFR2 (Fig. 8Da) and IL-1R (Fig. 8Ga) are also expressed by astrocytes (Fig. $8 B c, D c, G c$ ). There was a weak costaining of the microglial marker Iba1 (Fig. 8Eb, Hb) with TNFR2 (Fig. 8Ea) and or with IL-1R (Fig. $8 \mathrm{Ha}$ ). 

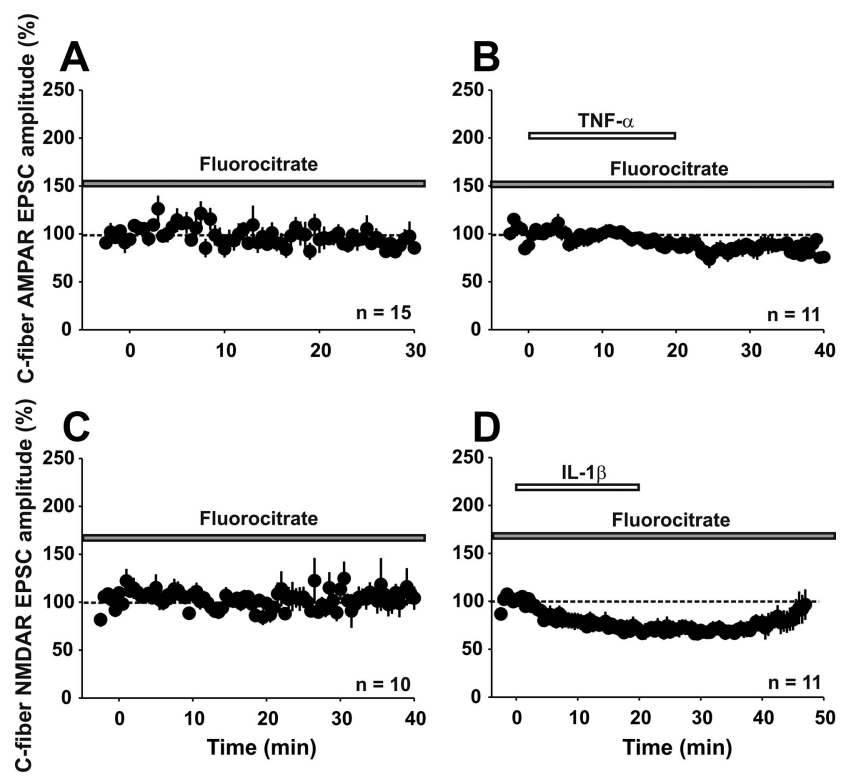

Figure 9. Effects of IL-1 $\beta$ and TNF- $\alpha$ are not mediated exclusively by neurons. Shown are means \pm SEM of AMPAR-evoked $(\boldsymbol{A}, \boldsymbol{B})$ or NMDAR-evoked $(\boldsymbol{C}, \boldsymbol{D})$ EPSC amplitudes calculated and plotted against time ( $\mathrm{min})$. $A$, In the presence of fluorocitrate $(5 \mathrm{~mm})$, AMPAR-evoked EPSC amplitudes stay stable over a recording period of $30 \min (n=15$ neurons, $p>0.05$, one-way RM ANOVA). $\boldsymbol{B}$, When slices are incubated with fluorocitrate, TNF- $\alpha(20 \mathrm{ng} / \mathrm{ml})$ has no effect on AMPAR-mediated currents ( $n=15$ neurons, $p>0.05$, one-way RM ANOVA). $C$, In the presence of fluorocitrate, NMDAR-mediated currents do not change significantly in 10 neurons over a recording period of $40 \mathrm{~min}(p>0.05$, one-way RM ANOVA). $\boldsymbol{D}$, After incubation with fluorocitrate, a 20 min application of IL-1 $\beta(20 \mathrm{ng} / \mathrm{ml})$ significantly decreases NMDAR-mediated currents ( $n=11$ neurons, $p<0.001$, one-way RM ANOVA).

Glial cells mediate neuronal actions of TNF- $\alpha$ and IL-1 $\beta$

Effects of TNF- $\alpha$ and IL-1 $\beta$ on glutamatergic currents are mediated via glial cells

All of the results obtained so far are compatible with the current view that cytokines act directly on neuronal receptors. However, as shown above, the respective cytokine receptors are also expressed on glial cells in the superficial spinal dorsal horn. Therefore, one cannot exclude that the effects of TNF- $\alpha$ and IL- $1 \beta$ are mediated via the activation of glial rather than neuronal cytokine receptors. To differentiate between direct neuronal and indirect, glial-mediated effects of cytokines, we repeated the experiments shown in Figure 6 in the presence of the glial cell inhibitor fluorocitrate. After a $2 \mathrm{~h}$ preincubation and during constant superfusion with fluorocitrate, AMPAR-mediated currents remained stable over the recording period (Fig. $9 A, n=15$ neurons, $92 \pm$ $2 \%$ of control after $30 \mathrm{~min}, p>0.05$, one-way RM ANOVA). Fluorocitrate fully prevented TNF- $\alpha$-induced potentiation of AMPAR-mediated currents (Fig. $9 B, n=11$ neurons, $89 \pm 2 \%$ of control $20 \mathrm{~min}$ after TNF- $\alpha$ application, $p>0.05$, one-way RM ANOVA). In the presence of fluorocitrate, NMDAR-mediated currents were stable within the recording period of $30 \mathrm{~min}$ (Fig. $9 C, n=10$ neurons, $106 \pm 6 \%$ of control, $p>0.05$, one-way RM ANOVA). Under the blockade of glial cells, IL- $1 \beta$ no longer increased but significantly reduced NMDAR-mediated synaptic transmission to $71 \pm 2 \%$ of control (Fig. $9 D, n=11$ neurons, $p<$ 0.001, one-way RM ANOVA). NMDAR-mediated currents returned to baseline levels 30 min after washout of IL-1 $\beta$ ( $92 \pm 2 \%$ of control, $p<0.05$, one-way RM ANOVA). The results demonstrate that activation of glial cells is an essential intermediate step for the enhancement of glutamatergic synaptic transmission by TNF- $\alpha$ or IL- $1 \beta$, respectively.
Table 1. IL-1 $\beta$ and TNF- $\alpha$ induce the release of a separate mixture of cytokines

\begin{tabular}{lll}
\hline Cytokines released (\% of control) & IL-1 $\beta$ & TNF- $\alpha$ \\
\hline CINC-2 & $299 \pm 70 \%^{*}$ & $150 \pm 32 \% *$ \\
CINC-3 & $374 \pm 98 \%^{*}$ & $230 \pm 92 \%$ \\
CNTF & $275 \pm 120 \%$ & $177 \pm 75 \% *$ \\
Fractalkine & $190 \pm 51 \%$ & $202 \pm 90 \%$ \\
GM-CSF & $255 \pm 39 \%^{*}$ & $127 \pm 47 \%$ \\
IFN- $\gamma$ & $290 \pm 68 \%^{*}$ & $123 \pm 35 \%$ \\
IL-1 $\alpha$ & $202 \pm 37 \%^{*}$ & $102 \pm 13 \%$ \\
IL-1 $\beta$ & - & $158 \pm 30 \% *$ \\
IL-4 & $234 \pm 24 \%^{*}$ & $186 \pm 40 \% *$ \\
IL-6 & $174 \pm 28 \% *$ & $260 \pm 74 \% *$ \\
IL-10 & $208 \pm 44 \%^{*}$ & $203 \pm 40 \% *$ \\
LIX & $214 \pm 38 \% *$ & $135 \pm 20 \%$ \\
Leptin & $182 \pm 56 \%$ & $225 \pm 75 \%$ \\
MCP-1 & $178 \pm 21 \%^{*}$ & $105 \pm 13 \%$ \\
MIP-3 & $217 \pm 35 \%^{*}$ & $121 \pm 16 \%$ \\
NGF & $117 \pm 13 \%$ & $121 \pm 13 \%$ \\
TIMP-1 & $205 \pm 47 \%$ & $121 \pm 18 \%$ \\
TNF- $\alpha$ & $235 \pm 39 \%^{*}$ & - \\
VEGF & $163 \pm 38 \%$ & $137 \pm 15 \% *$ \\
\hline
\end{tabular}

Table lists all cytokines that were tested to be released upon incubation with IL- $1 \beta(20 \mathrm{ng} / \mathrm{ml})$ or TNF- $\alpha(20 \mathrm{ng} / \mathrm{ml})$. Experiments were performed in which four slices were incubated with IL-1 $\beta$ or TNF- $\alpha$ or treated as control. After 20 $\min$, the supernatant was used to analyze the release of the 19 cytokines listed here. Although IL- $1 \beta$ induced a significant increase in CINC-2, CINC-3, GM-CSF, IFN- $\gamma$, IL- $1 \alpha$, IL-4, IL-6, IL-10, LIX, MCP-1, MIP-3, and TNF- $\alpha$ ( ${ }^{*} p<$ 0.05 compared with control, $n=5$ experiments, $t$ test), TNF- $\alpha$ did induce a significant increase in (INC-2, CNTF, $\mathrm{IL}-1 \beta$, IL-4, IL-6, IL-10, and VEGF ( ${ }^{*} p<0.05$ compared with control, $n=10$ experiments, $t$ test). Other cytokines listed here are fractalkine, leptin, nerve growth factor (NGF), and TIMP metallopeptidase inhibitor-1 (TIMP-1).

\section{TNF- $\alpha$ and $I L-1 \beta$ induce the release of cytokines in the} spinal cord

From our finding that the differential effects of TNF- $\alpha$ and IL-1 $\beta$ on synaptic AMPAR- and NMDAR-mediated currents are mediated indirectly via activation of glial cells, one can predict that TNF- $\alpha$ and IL- $1 \beta$ trigger the release of distinct mixtures of neuroactive substances from glial cells. To test this hypothesis directly, we screened for cytokines, chemokines, and neurotrophic factors that are released into the spinal cord slice supernatant upon TNF- $\alpha$ or IL- $1 \beta$ stimulation. We incubated spinal cord slices with TNF- $\alpha$ (20 or $40 \mathrm{ng} / \mathrm{ml})$ or IL-1 $\beta$ (20 ng/ml) for 20 $\mathrm{min}$ and assessed the release profiles in the supernatant of naive and cytokine-treated slices. IL- $1 \beta$ significantly increased the levels of a number of molecules, including cytokine-induced neutrophil chemoattractant 2 (CINC-2), CINC-3, granulocytemacrophage colony-stimulating factor (GM-CSF), interferon gamma (IFN- $\gamma$ ), IL-1 $\alpha$, IL-4, IL-6, IL-10, lipopoysaccharide CXC chemokine (LIX), monocyte chemotactic protein 1 (MCP1 ), macrophage inflammatory protein-3 (MIP-3), and TNF- $\alpha$ (Table $1, p<0.05, t$ test, $n=5$ experiments) compared with control conditions ( $n=5$ experiments). In contrast, and consistent with our hypothesis, TNF- $\alpha$ induced the upregulation of another, only partially overlapping set of cytokines, including CINC-2, ciliary neurotrophic factor (CNTF), IL-1 $\beta$, IL-4, IL-6, IL-10, and vascular endothelial growth factor (VEGF; Table 1, $n=10$ experiments, $p<0.05, t$ test $)$.

\section{Role of glial cells, IL-1 $\beta$, and TNF- $\alpha$ in vivo}

We next investigated whether our in vitro findings had any relevance for the intact animal.

\section{Role of glia and cytokines for LTP induction of C-fiber-evoked field potentials}

We applied conditioning HFS at C-fiber strength to the left sciatic nerve. This induced LTP of C-fiber-evoked field potentials in ipsilateral spinal laminae I/II that lasted undiminished for at least 60 min (Fig. 10B, $n=8$ animals, $p<0.001$, one-way $\mathrm{RM}$ 
A

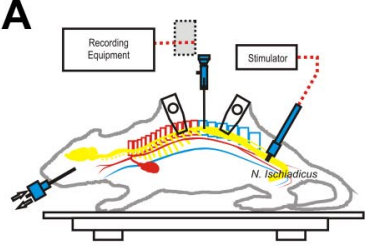

$B_{25}$

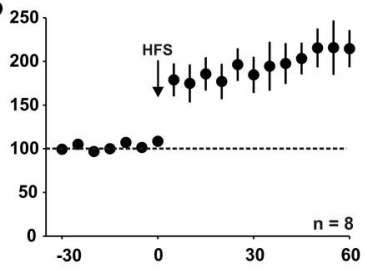

C

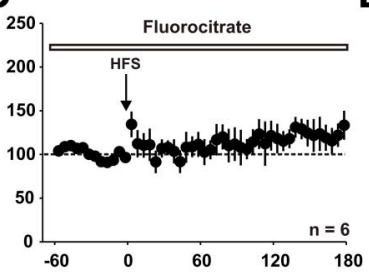

D

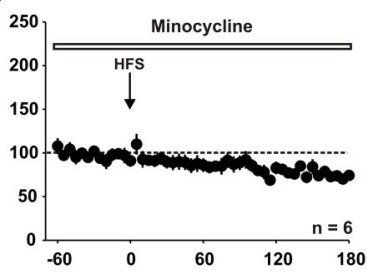

$E$

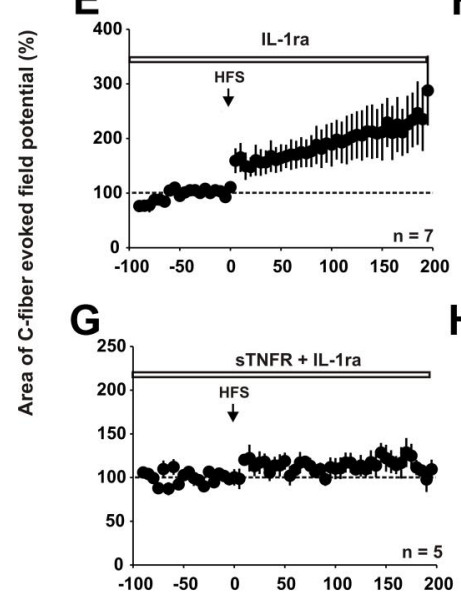

$F$

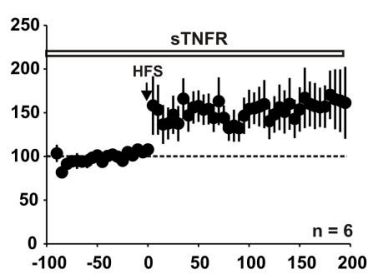

$\mathrm{H}$

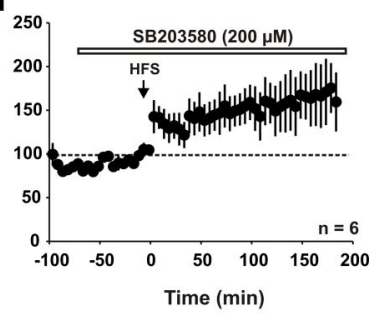

$\mathrm{J}$

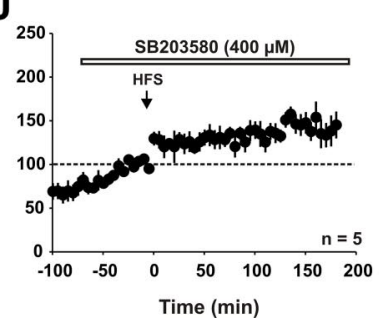

Figure 10. Inhibition of glial cells and IL-1 $\beta$ and TNF- $\alpha$ together prevents LTP induction after HFS in vivo. In $\boldsymbol{A}-\boldsymbol{E}$, the area of the (-fiber-evoked field potential is plotted against time (min). Data are expressed as mean \pm SEM. $A$, Schematic drawing of the recording setup for in vivo experiments. $\boldsymbol{B}$, Averaged time course of $C$-fiber-evoked field potentials recorded from eight rats in which HFS induces LTP ( $p<0.001$, one-way RM ANOVA). Values were normalized to pretreatment values (dotted line) and plotted against time. C, Spinal superfusion with the glial inhibitor fluorocitrate $(0.01 \mathrm{~mm})$ abolished the induction of LTP by HFS ( $n=6$ animals, $p>0.05$, one-way RM ANOVA). $\boldsymbol{D}$, Intravenous infusion of minocycline $(60 \mathrm{mg} / \mathrm{kg})$ beginning $1 \mathrm{~h}$ before the start of the experiment (open horizontal bar) prevents LTP induction by HFS ( $n=6$ animals, $p<0.001$ compared with HFS control animals $60 \mathrm{~min}$ after HFS, $t$ test). $\boldsymbol{E}$, Spinal superfusion at the recording segment with IL-1ra (400 $\mathrm{ng} / 10 \mu \mathrm{l})$ does not influence the establishment of spinal LTP after HFS ( $n=7$ animals, $p<0.05$, one-way RM ANOVA). $\boldsymbol{F}$, Spinal superfusion with sTNFR does also not prevent the induction of spinal LTP after HFS ( $n=6$ animals, $p<$ 0.05 , one-way RM ANOVA). G, The combination of IL-1ra and sTNFR prevents LTP induction after HFS ( $n=5$ animals, $p>0.05$, one-way RM ANOVA). $\boldsymbol{H}$, The p-p38 MAPK blocker SB203580 (200 $\mu \mathrm{M})$ does not have any effect on HFS-induced LTP ( $n=6$ animals, $p<$ 0.05 , one-way RM ANOVA). J, A higher dose of SB203580 (400 $\mu \mathrm{M})$ significantly reduces HFS-induced LTP compared with control animals 60 min after HFS $(\boldsymbol{B} ; n=5$ animals; $p<$ $0.05, t$ test).
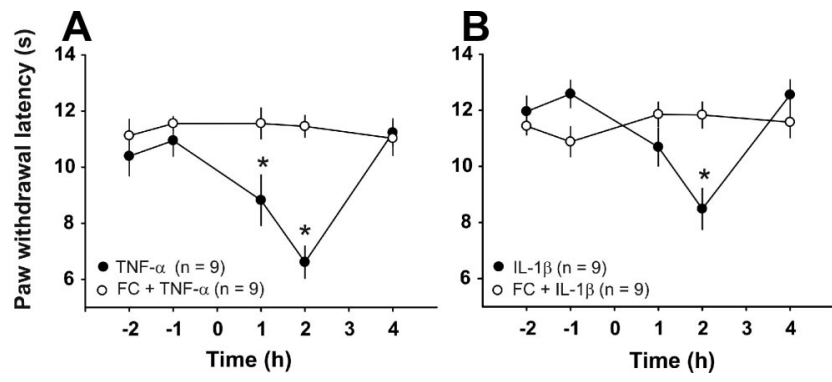

Figure 11. IL-1 $\beta$ - and TNF- $\alpha$-induced hyperalgesia are prevented by glial cell blockade. $A$ Intrathecal injection of TNF- $\alpha$ ( $20 \mathrm{ng}$ in $10 \mu \mathrm{l}$ of saline) induces a significant reduction in the withdrawal latency in response to a radiant heat source compared with baseline levels $(n=9$ animals, $p<0.001$, two-way RM ANOVA). Intrathecal injection of fluorocitrate ( $1 \mathrm{nmol}$ in $10 \mu \mathrm{l}$ of saline) $2 \mathrm{~h}$ before TNF- $\alpha$ fully prevents cytokine-induced hyperalgesia ( $n=9$ animals, $p>$ 0.05 , two-way RM ANOVA). $\boldsymbol{B}$, Spinal injection of IL-1 $\beta$ ( $20 \mathrm{ng}$ in $10 \mu \mathrm{l}$ of saline) induces heat hyperalgesia in nine animals tested ( $p<0.001$, two-way RM ANOVA). Fluorocitrate inhibits IL- $1 \beta$-induced hyperalgesia significantly ( $n=9$ animals, $p>0.05$, two-way RM ANOVA).

ANOVA). Superfusion of the spinal cord dorsum at the recording site with fluorocitrate $(0.01 \mathrm{mM})$ prevented the induction of LTP by HFS. Mean C-fiber-evoked field potentials stayed at $110 \pm$ $14 \%$ of control (Fig. 10C, $n=6$ animals, $p>0.05$, one-way RM ANOVA). Systemic administration of minocycline $(60 \mathrm{mg} / \mathrm{kg})$ also prevented the induction of LTP by HFS (Fig. 10D, $n=6$ animals, $p>0.05$, one-way RM ANOVA). We next investigated whether the blockade of IL- $1 \beta$ and/or TNF- $\alpha$ prevented LTP induction by HFS in vivo. Spinal superfusion with IL-1ra (Fig. $10 E, n=7$ animals) or sTNFR (Fig. $10 F, n=6$ animals) did not affect LTP induction by HFS (both $p<0.05$, one-way RM ANOVA). In contrast, simultaneous application of IL-1ra and sTNFR1 abolished the induction of LTP at C-fiber synapses by HFS (Fig. 10G, $n=5$ animals, $p>0.05$, one-way RM ANOVA). We then investigated whether the blockade of p-p38 MAPK by SB203580 at $200 \mu \mathrm{M}$ has any effect on HFS-induced LTP. Spinal application of SB203580, which has been shown to block ATPinduced LTP at this concentration, did not affect HFS-induced LTP (Fig. $10 H, n=6$ animals, $p<0.05$, one-way RM ANOVA). At a higher concentration $(400 \mu \mathrm{M})$, SB203580 significantly reduced but failed to abolish HFS-induced LTP (Fig. 10J, $n=5$ animals, to $129 \pm 11 \%$ of baseline $60 \mathrm{~min}$ after HFS compared with control conditions; Fig. 10B, $p<0.05$, $t$ test).

Cytokine effects on nociceptive behavior are mediated by spinal glial cells

The results of the in vitro experiments raised the question of whether the pro-nociceptive effects of TNF- $\alpha$ and IL- $1 \beta$ in behaving animals are also mediated indirectly via the activation of glial cells. We thus investigated whether TNF- $\alpha$ or IL- $1 \beta$ induced thermal hyperalgesia in the presence of the glial cell inhibitor fluorocitrate. Intrathecal application of TNF- $\alpha$ robustly induced heat hyperalgesia in all nine animals tested (Fig. $11 A, p<0.001$ compared with control, two-way RM ANOVA). An intrathecal injection of the glial inhibitor fluorocitrate $2 \mathrm{~h}$ before the TNF- $\alpha$ injection fully prevented the development of TNF- $\alpha$-induced hyperalgesia (Fig. 11A, $n=9$ animals, $p>0.05$ compared with control, two-way RM ANOVA). Likewise, intrathecal injection of IL- $1 \beta$ induced heat hyperalgesia in all nine animals tested (Fig. $11 B, p<0.001$ compared with control, two-way RM ANOVA). Fluorocitrate also abolished the IL- $1 \beta$-induced hyperalgesia (Fig. $11 B, p>0.05$ compared with control, $n=9$ animals, two-way RM ANOVA). These data suggest that cytokine-induced hyperalgesia requires activation of spinal glial cells. 


\section{Discussion}

The present study revealed essentially four novel findings. First, we have provided evidence for the rapid involvement of microglia and astrocytes in LTP induction at C-fiber synapses with spinal lamina I neurons. Second, we found that the proinflammatory cytokines IL- $1 \beta$ and TNF- $\alpha$ are individually sufficient, with activation of either signaling pathway being necessary for the induction of LTP at C-fiber synapses with spinal lamina I neurons. Third, we showed that neurons, microglia, and astrocytes in the spinal dorsal horn express cytokine receptors for IL- $1 \beta$ and TNF- $\alpha$. Fourth, in contrast to the current view, the induction of both synaptic LTP and hyperalgesia by IL- $1 \beta$ and TNF- $\alpha$ are not direct neuronal effects but are mediated indirectly via activation of spinal glial cells.

Minocycline or fluorocitrate, which have been used to block glial cell functions, prevent induction of LTP at C-fiber synapses with spinal lamina I neurons in vitro (present study) and in superficial spinal dorsal horn in vivo (present study and Ma and Zhao, 2002; Zhong et al., 2010; Chu et al., 2012). This suggests a decisive role of glia for plasticity at C-fiber synapses (Scholz and Woolf, 2007; Milligan and Watkins, 2009; Sandkühler, 2009). However, other potential mechanisms must not be ruled out because the effects of these blockers are not specific (McMahon and Malcangio, 2009). If the activation of glia should indeed be essential for inducing LTP, then conditioning HFS of primary afferents must activate spinal glial cells quite rapidly (i.e., within few minutes). This has thus far not been demonstrated. Using immunohistochemical markers for the activation of glia, we found that HFS activates microglia within $30 \mathrm{~min}$ and astrocytes within $2 \mathrm{~h}$. These delays are too long to be compatible with any contribution of spinal glial cells to the induction of LTP. $\mathrm{Ca}^{2+}$ imaging revealed that HFS activates astrocytes in superficial dorsal horn within 2-3 s, which is fully compatible with their involvement in LTP induction.

We next investigated which molecules mediate glia-to-neuron signaling. IL- $1 \beta$ and TNF- $\alpha$ are good candidates because both cytokines are synthesized, stored as their inactive precursors, and released upon stimulation from glia (Dinarello, 1991; Soma et al., 1995). We found that both cytokines enhanced synaptic AMPAR- and/or NMDAR-mediated currents in lamina I neurons and induced LTP in a significant proportion of neurons. Amplification of synaptic strength between C-fibers and lamina I (present study) and lamina II neurons (Kawasaki et al., 2008; Park et al., 2011; Zhang et al., 2011) by IL-1 $\beta$ and/or TNF- $\alpha$ are potential mechanisms underlying the hyperalgesia that can be evoked by either of these cytokines (Watkins et al., 1994; Sung et al., 2004; Kawasaki et al., 2008).

IL- $1 \beta$ enhanced synaptic NMDAR-mediated currents in lamina I neurons and this was associated with the NR1 phosphorylation at Ser896, a protein-kinase-C-dependent site. Phosphorylation at Ser896 may contribute to the trafficking of NMDARs to the membrane (Brenner et al., 2004). NR1 phosphorylation is also increased in animals after peripheral nerve injury, which requires IL-1 $\beta$ and TNF- $\alpha$ signaling (Wei et al., 2008). Enhanced NMDAR activity affects a number of neuronal functions, including the induction of LTP at C-fiber synapses (Ikeda et al., 2006; Drdla et al., 2009), "wind-up" of action potential discharges (Suzuki et al., 2001), strength of synaptic inhibition (Lee et al., 2011), and apoptosis (Yu et al., 1999). TNF- $\alpha$ and IL-1 $\beta$ decrease inhibitory synaptic transmission in the spinal dorsal horn (Kawasaki et al., 2008; Zhang and Dougherty, 2011) and TNF- $\alpha$ decreases the expression of neuronal $\mathrm{K}^{+}$channels (Diem et al., 2001). IL-1 $\beta$ facilitates TRPV1-mediated currents in DRG neurons (Piper et al., 1999) and may induce presynaptic facilitation involving TRPV1-expressing fibers and excitatory (vGLUT2-expressing) spinal dorsal horn neurons (Park et al., 2011). All of this is potentially relevant to spinal nociception and to a variety of experimental and clinically forms of pain (Kolhekar and Gebhart, 1996; Chaplan et al., 1997; Laughlin et al., 1997; Guo et al., 2002).

TNF- $\alpha$ and IL- $1 \beta$ are individually sufficient, but only one is also required for LTP induction between primary afferent $\mathrm{C}$-fibers and spinal lamina I neurons after HFS. This suggests some redundancy in the effects of TNF- $\alpha$ and IL- $1 \beta$ on synaptic plasticity. For example, both cytokines lead to the activation of NF- $\kappa \mathrm{B}$ in glia and in neurons (Kettenmann and Ransom, 1995). In contrast, at C-fiber synapses with lamina II neurons, LTP cannot be induced in TNFR1 or TNFR2 knockout mice (Park et al., 2011).

According to the prevailing view, the synaptic effects of IL- $1 \beta$ and TNF- $\alpha$ are mediated by direct actions on neurons (McMahon and Malcangio, 2009; Milligan and Watkins, 2009; Gao and Ji, 2010b). consistent with this, IL-1R (Samad et al., 2001; Zhang et al., 2008) and TNFR1 (Ohtori et al., 2004; Xu et al., 2006; Zhang and Dougherty, 2011) have been identified on spinal dorsal horn neurons or on primary afferent terminals (Holmes et al., 2004). In the present study, we also found a colocalization of TNFR1, IL-1R, and a scarce colocalization of TNFR2 with spinal lamina I neurons. In addition, we identified TNFR1 and IL-1R on astrocytes and a weaker colocalization with microglia. Although our findings are consistent with the classical, direct action of IL- $1 \beta$ and TNF- $\alpha$ on superficial dorsal horn neurons, they also point to an alternative signaling pathway in which cytokines act on glial cytokine receptors. Activation of glial cells leads to the release of further cytokines, chemokines, and gliotransmitters and the downregulation of glial glutamate transporters (Korn et al., 2005; Sitcheran et al., 2005). All of this may amplify glutamatergic synaptic transmission.

In support of this hypothesis, we found that in the presence of fluorocitrate, TNF- $\alpha$ failed to potentiate AMPAR-mediated synaptic currents and IL- $1 \beta$ depressed, rather than potentiated, NMDAR-mediated currents. This suggests that both cytokines need to activate glia to facilitate glutamatergic transmission at C-fiber synapses. The depressant synaptic effect of IL-1 $\beta$ in the presence of fluorocitrate is likely mediated by a direct action on neuronal IL-1Rs, for example, by depression of voltagedependent calcium channels (Rada et al., 1991). A direct neuronal inhibition and an indirect, glia-mediated facilitation by IL- $1 \beta$ is consistent with the observation that IL- $1 \beta$ decreases wind-up of action potential discharges in animals with disrupted glial cell function but enhances wind-up in naive animals (Constandil et al., 2009). With glial cell function intact, IL- $1 \beta$ regularly depresses glutamatergic synaptic transmission and LTP induction in the hippocampus (Murray and Lynch, 1998; Pickering and O'Connor, 2007), suggesting that, unlike the case in the superficial dorsal horn, glial cell-mediated facilitatory effects of IL- $1 \beta$ either do not exist or do not prevail over inhibition at synapses in the hippocampus.

The absence of any synaptic facilitation or thermal hyperalgesia by IL- $1 \beta$ or TNF- $\alpha$ in the presence of fluorocitrate suggests that glial cell activation and the release of unknown mixtures of glial mediators are indispensable intermediate steps for their pronociceptive effects. To demonstrate that bath application of IL- $1 \beta$ or TNF- $\alpha$ activates spinal glia (Watkins et al., 2007; Wei et al., 2008; Gao and Ji, 2010b) and to find potential glial factors that contribute to the excitatory effects of IL- $1 \beta$ or TNF- $\alpha$, we tested 
the release of typical glial mediators after IL- $1 \beta$ and TNF- $\alpha$ application.

TNF- $\alpha$ triggers the release of IL- $1 \beta$ and this is required for TNF- $\alpha$-induced hyperalgesia (Watkins et al., 1995). One would thus expect that the IL- $1 \beta$ release profile is a subset of the TNF- $\alpha$ release profile. We found indeed that TNF- $\alpha$ triggered the release of IL- $1 \beta$ and both triggered the release of CINC-2, IL-4, IL- 6 , and IL-10. Nonetheless, the majority of glial mediators were released by bath application of IL- $1 \beta$ but not by TNF- $\alpha$, including CINC-3, GM-CSF, IFN- $\gamma$, IL- $1 \alpha$, LIX3, MIP-3, and MCP-1. MCP-1 has been implicated previously in neuron-to-microglial signaling (Thacker et al., 2009). A recent study has demonstrated a novel role of MCP-1 in astroglia-to-neuron signaling after nerve injury by rapidly increasing the activity of NMDARs in spinal dorsal horn neurons (Gao and Ji, 2010a). IL-1 $\beta$, but not TNF- $\alpha$, also induced a significant release of IFN- $\gamma$, the classical activator of microglia/macrophages that drives the development of neuropathic pain (Tsuda et al., 2009). The release profiles of IL- $1 \beta$ and TNF- $\alpha$ indicate that, under the given experimental conditions, IL- $1 \beta$ release by TNF- $\alpha$ was insufficient to exploit the full IL- $1 \beta$ release profile. Nevertheless, the release profiles of both cytokines match the pro-inflammatory activation pattern of microglia/macrophages found after stimulation with IFN- $\gamma$ or LPS (Sun et al., 2004; Clark et al., 2006), including the release of CINC-2, IL-1 $\beta$, IL-6, and/or TNF- $\alpha$ (Nakagawa et al., 1996; Ishihara and Hirano, 2002; Town et al., 2005; Clark et al., 2010; Belarbi et al., 2012). Surprisingly, both cytokines also lead to the release of anti-inflammatory cytokines, including IL-4, IL-10, and VEGF, suggesting that spinal glial cells can express and release pro- and anti-inflammatory cytokines simultaneously.

Our study has revealed a novel signaling cascade leading to LTP at C-fiber synapses in spinal cord lamina I and to thermal hyperalgesia. Activity in primary afferent $\mathrm{C}$-fibers leads to the activation of glial cells and to the release of IL- $1 \beta$ and TNF- $\alpha$. These cytokines directly or indirectly activate spinal glial cells, which by the release of distinct glial mediators then trigger both LTP at C-fiber synapses and hyperalgesia.

\section{References}

Beattie EC, Stellwagen D, Morishita W, Bresnahan JC, Ha BK, Von Zastrow M, Beattie MS, Malenka RC (2002) Control of synaptic strength by glial TNF $\alpha$. Science 295:2282-2285. CrossRef Medline

Belarbi K, Jopson T, Tweedie D, Arellano C, Luo W, Greig NH, Rosi S (2012) TNF- $\alpha$ protein synthesis inhibitor restores neuronal function and reverses cognitive deficits induced by chronic neuroinflammation. J Neuroinflammation 9:23. CrossRef Medline

Brenner GJ, Ji RR, Shaffer S, Woolf CJ (2004) Peripheral noxious stimulation induces phosphorylation of the NMDA receptor NR1 subunit at the PKC-dependent site, serine-896, in spinal cord dorsal horn neurons. Eur J Neurosci 20:375-384. CrossRef Medline

Butler MP, O'Connor JJ, Moynagh PN (2004) Dissection of tumor-necrosis factor- $\alpha$ inhibition of long-term potentiation (LTP) reveals a p38 mitogen-activated protein kinase-dependent mechanism which maps to early-but not late-phase LTP. Neuroscience 124:319-326. CrossRef Medline

Chaplan SR, Malmberg AB, Yaksh TL (1997) Efficacy of spinal NMDA receptor antagonism in formalin hyperalgesia and nerve injury evoked allodynia in the rat. J Pharmacol Exp Ther 280:829-838. Medline

Chen J, Sandkühler J (2000) Induction of homosynaptic long-term depression at spinal synapses of sensory A $\delta$-fibers requires activation of metabotropic glutamate receptors. Neuroscience 98:141-148. CrossRef Medline

Chu Y-X, Zhang YQ, Zhao ZQ (2012) Involvement of microglia and interleukin-18 in the induction of long-term potentiation of spinal nociceptive responses induced by tetanic sciatic stimulation. Neurosci Bull 28:49-60. CrossRef Medline

Clark AK, D’Aquisto F, Gentry C, Marchand F, McMahon SB, Malcangio M
(2006) Rapid co-release of interleukin $1 \beta$ and caspase 1 in spinal cord inflammation. J Neurochem 99:868-880. CrossRef Medline

Clark AK, Yip PK, Malcangio M (2009) The liberation of fractalkine in the dorsal horn requires microglial cathepsin S. J Neurosci 29:6945-6954. CrossRef Medline

Clark AK, Staniland AA, Marchand F, Kaan TK, McMahon SB, Malcangio M (2010) P2X7-dependent release of interleukin- $1 \beta$ and nociception in the spinal cord following lipopolysaccharide. J Neurosci 30:573-582. CrossRef Medline

Constandil L, Hernández A, Pelissier T, Arriagada O, Espinoza K, Burgos H, Laurido C (2009) Effect of interleukin-1 $\beta$ on spinal cord nociceptive transmission of normal and monoarthritic rats after disruption of glial function. Arthritis Res Ther 11:R105. CrossRef Medline

Diem R, Meyer R, Weishaupt JH, Bahr M (2001) Reduction of potassium currents and phosphatidylinositol 3-kinase-dependent AKT phosphorylation by tumor necrosis factor- $\alpha$ rescues axotomized retinal ganglion cells from retrograde cell death in vivo. J Neurosci 21:2058-2066. Medline

Dinarello CA (1991) Interleukin-1 and interleukin-1 antagonism. Blood 77: 1627-1652. Medline

Dodt HU, Zieglgänsberger W (1990) Visualizing unstained neurons in living brain slices by infrared DIC-videomicroscopy. Brain Res 537:333336. CrossRef Medline

Drdla R, Gassner M, Gingl E, Sandkühler J (2009) Induction of synaptic long-term potentiation after opioid withdrawal. Science 325:207-210. CrossRef Medline

Galan A, Laird JM, Cervero F (2004) In vivo recruitment by painful stimuli of AMPA receptor subunits to the plasma membrane of spinal cord neurons. Pain 112:315-323. CrossRef Medline

Gao YJ, Ji RR (2010a) Chemokines, neuronal-glial interactions, and central processing of neuropathic pain. Pharmacol Ther 126:56-68. CrossRef Medline

Gao YJ, Ji RR (2010b) Targeting astrocyte signaling for chronic pain. Neurotherapeutics 7:482-493. CrossRef Medline

Guo W, Zou S, Guan Y, Ikeda T, Tal M, Dubner R, Ren K (2002) Tyrosine phosphorylation of the NR2B subunit of the NMDA receptor in the spinal cord during the development and maintenance of inflammatory hyperalgesia. J Neurosci 22:6208-6217. Medline

Guo W, Wang H, Watanabe M, Shimizu K, Zou S, LaGraize SC, Wei F, Dubner R, Ren K (2007) Glial-cytokine-neuronal interactions underlying the mechanisms of persistent pain. J Neurosci 27:6006-6018. CrossRef Medline

Henry CJ, Huang Y, Wynne A, Hanke M, Himler J, Bailey MT, Sheridan JF, Godbout JP (2008) Minocycline attenuates lipopolysaccharide (LPS)induced neuroinflammation, sickness behavior, and anhedonia. J Neuroinflammation 5:15. CrossRef Medline

Holmes GM, Hebert SL, Rogers RC, Hermann GE (2004) Immunocytochemical localization of TNF type 1 and type 2 receptors in the rat spinal cord. Brain Res 1025:210-219. CrossRef Medline

Ikeda H, Heinke B, Ruscheweyh R, Sandkühler J (2003) Synaptic plasticity in spinal lamina I projection neurons that mediate hyperalgesia. Science 299:1237-1240. CrossRef Medline

Ikeda H, Stark J, Fischer H, Wagner M, Drdla R, Jäger T, Sandkühler J (2006) Synaptic amplifier of inflammatory pain in the spinal dorsal horn. Science 312:1659-1662. CrossRef Medline

Ishihara K, Hirano T (2002) IL-6 in autoimmune disease and chronic inflammatory proliferative disease. Cytokine Growth Factor Rev 13:357368. CrossRef Medline

Kawasaki Y, Zhang L, Cheng JK, Ji RR (2008) Cytokine mechanisms of central sensitization: distinct and overlapping role of interleukin- $1 \beta$, interleukin-6, and tumor necrosis factor- $\alpha$ in regulating synaptic and neuronal activity in the superficial spinal cord. J Neurosci 28:5189-5194. CrossRef Medline

Kettenmann H, Ransom BR (1995) Neuroglia. New York: Oxford.

Kim HY, Lee KY, Lu Y, Wang J, Cui L, Kim SJ, Chung JM, Chung K (2011) Mitochondrial $\mathrm{Ca}^{2+}$ uptake is essential for synaptic plasticity in pain. J Neurosci 31:12982-12991. CrossRef Medline

Kolhekar R, Gebhart GF (1996) Modulation of spinal visceral nociceptive transmission by NMDA receptor activation in the rat. J Neurophysiol 75:2344-2353. Medline

Korn T, Magnus T, Jung S (2005) Autoantigen specific T cells inhibit glutamate uptake in astrocytes by decreasing expression of astrocytic glutamate 
transporter GLAST: a mechanism mediated by tumor necrosis factor- $\alpha$. FASEB J 19:1878-1880. CrossRef Medline

Kremlev SG, Roberts RL, Palmer C (2004) Differential expression of chemokines and chemokine receptors during microglial activation and inhibition. J Neuroimmunol 149:1-9. CrossRef Medline

Laughlin TM, Vanderah TW, Lashbrook J, Nichols ML, Ossipov M, Porreca F, Wilcox GL (1997) Spinally administered dynorphin A produces longlasting allodynia: involvement of NMDA but not opioid receptors. Pain 72:253-260. CrossRef Medline

Lee HH, Deeb TZ, Walker JA, Davies PA, Moss SJ (2011) NMDA receptor activity downregulates $\mathrm{KCC} 2$ resulting in depolarizing $\mathrm{GABA}_{\mathrm{A}}$ receptormediated currents. Nat Neurosci 14:736-743. CrossRef Medline

Li M, Shi J, Tang JR, Chen D, Ai B, Chen J, Wang LN, Cao FY, Li LL, Lin CY, Guan XM (2005) Effects of complete Freund's adjuvant on immunohistochemical distribution of IL- $1 \beta$ and IL-1R I in neurons and glia cells of dorsal root ganglion. Acta Pharmacol Sin 26:192-198. CrossRef Medline

Liu YL, Zhou LJ, Hu NW, Xu JT, Wu CY, Zhang T, Li YY, Liu XG (2007) Tumor necrosis factor- $\alpha$ induces long-term potentiation of C-fiber evoked field potentials in spinal dorsal horn in rats with nerve injury: the role of NF-kappa B, JNK and p38 MAPK. Neuropharmacology 52:708715. CrossRef Medline

Ma JY, Zhao ZQ (2002) The involvement of glia in long-term plasticity in the spinal dorsal horn of the rat. Neuroreport 13:1781-1784. CrossRef Medline

Mantyh PW, Rogers SD, Honoré P, Allen BJ, Ghilardi JR, Li J, Daughters RS, Lappi DA, Wiley RG, Simone DA (1997) Inhibition of hyperalgesia by ablation of lamina I spinal neurons expressing the substance P receptor. Science 278:275-279. CrossRef Medline

McMahon SB, Malcangio M (2009) Current challenges in glia-pain biology. Neuron 64:46-54. CrossRef Medline

Milligan ED, Watkins LR (2009) Pathological and protective roles of glia in chronic pain. Nat Rev Neurosci 10:23-36. CrossRef Medline

Murray CA, Lynch MA (1998) Evidence that increased hippocampal expression of the cytokine interleukin- $1 \beta$ is a common trigger for age- and stress-induced impairments in long-term potentiation. J Neurosci 18: 2974-2981. Medline

Nakagawa H, Shiota S, Takano K, Shibata F, Kato H (1996) Cytokineinduced neutrophil chemoattractant (CINC)-2 $\alpha$, a novel member of rat GRO/CINCs, is a predominant chemokine produced by lipopolysaccharide-stimulated rat macrophages in culture. Biochem Biophys Res Commun 220:945-948. CrossRef Medline

Nichols ML, Allen BJ, Rogers SD, Ghilardi JR, Honoré P, Luger NM, Finke MP, Li J, Lappi DA, Simone DA, Mantyh PW (1999) Transmission of chronic nociception by spinal neurons expressing the substance P receptor. Science 286:1558-1561. CrossRef Medline

Ohtori S, Takahashi K, Moriya H, Myers RR (2004) TNF- $\alpha$ and TNF- $\alpha$ receptor type 1 upregulation in glia and neurons after peripheral nerve injury: studies in murine DRG and spinal cord. Spine 29:1082-1088. CrossRef Medline

Park CK, Lü N, Xu ZZ, Liu T, Serhan CN, Ji RR (2011) Resolving TRPV1and TNF- $\alpha$-mediated spinal cord synaptic plasticity and inflammatory pain with neuroprotectin D1. J Neurosci 31:15072-15085. CrossRef Medline

Pickering M, O'Connor JJ (2007) Pro-inflammatory cytokines and their effects in the dentate gyrus. Prog Brain Res 163:339-354. CrossRef Medline

Piper AS, Yeats JC, Bevan S, Docherty RJ (1999) A study of the voltage dependence of capsaicin-activated membrane currents in rat sensory neurones before and after acute desensitization. J Physiol 518:721-733. CrossRef Medline

Rada P, Mark GP, Vitek MP, Mangano RM, Blume AJ, Beer B, Hoebel BG (1991) Interleukin- $1 \beta$ decreases acetylcholine measured by microdialysis in the hippocampus of freely moving rats. Brain Res 550:287-290. CrossRef Medline

Richards N, Batty T, Dilley A (2011) CCL2 has similar excitatory effects to TNF- $\alpha$ in a subgroup of inflamed C-fiber axons. J Neurophysiol 106: 2838-2848. CrossRef Medline

Samad TA, Moore KA, Sapirstein A, Billet S, Allchorne A, Poole S, Bonventre JV, Woolf CJ (2001) Interleukin-1 $\beta$-mediated induction of Cox-2 in the CNS contributes to inflammatory pain hypersensitivity. Nature 410:471-475. CrossRef Medline

Sandkühler J (2009) Models and mechanisms of hyperalgesia and allodynia. Physiol Rev 89:707-758. CrossRef Medline
Schäfers M, Geis C, Svensson CI, Luo ZD, Sommer C (2003) Selective increase of tumour necrosis factor-alpha in injured and spared myelinated primary afferents after chronic constrictive injury of rat sciatic nerve. Eur J Neurosci 17:791-804. CrossRef Medline

Scholz J, Woolf CJ (2007) The neuropathic pain triad: neurons, immune cells and glia. Nat Neurosci 10:1361-1368. CrossRef Medline

Sitcheran R, Gupta P, Fisher PB, Baldwin AS (2005) Positive and negative regulation of EAAT2 by NF- $\kappa$ B: a role for N-myc in TNF $\alpha$-controlled repression. EMBO J 24:510-520. CrossRef Medline

Soma IG, Nishizawa T, Inagawa H, Tanabe Y, Noguchi K, Goto S, Takagi K, Mizuno D (1995) Bidirectional feedback regulation on $17 \mathrm{kD}$ tumor necrosis factor (TNF) production by $26 \mathrm{kD}$ membrane-bound TNF precursor. J Inflamm 47:52-60. Medline

Sun D, Newman TA, Perry VH, Weller RO (2004) Cytokine-induced enhancement of autoimmune inflammation in the brain and spinal cord: implications for multiple sclerosis. Neuropathol Appl Neurobiol 30:374-384. CrossRef Medline

Sung CS, Wen ZH, Chang WK, Ho ST, Tsai SK, Chang YC, Wong CS (2004) Intrathecal interleukin- $1 \beta$ administration induces thermal hyperalgesia by activating inducible nitric oxide synthase expression in the rat spinal cord. Brain Res 1015:145-153. CrossRef Medline

Suzuki R, Matthews EA, Dickenson AH (2001) Comparison of the effects of MK-801, ketamine and memantine on responses of spinal dorsal horn neurones in a rat model of mononeuropathy. Pain 91:101-109. CrossRef Medline

Svensson CI, Marsala M, Westerlund A, Calcutt NA, Campana WM, Freshwater JD, Catalano R, Feng Y, Protter AA, Scott B, Yaksh TL (2003) Activation of p38 mitogen-activated protein kinase in spinal microglia is a critical link in inflammation-induced spinal pain processing. J Neurochem 86:1534-1544. CrossRef Medline

Svensson CI, Fitzsimmons B, Azizi S, Powell HC, Hua XY, Yaksh TL (2005) Spinal p $38 \beta$ isoform mediates tissue injury-induced hyperalgesia and spinal sensitization. J Neurochem 92:1508-1520. CrossRef Medline

Thacker MA, Clark AK, Bishop T, Grist J, Yip PK, Moon LD, Thompson SW, Marchand F, McMahon SB (2009) CCL2 is a key mediator of microglia activation in neuropathic pain states. Eur J Pain 13:263-272. CrossRef Medline

Town T, Nikolic V, Tan J (2005) The microglial "activation" continuum: from innate to adaptive responses. J Neuroinflammation 2:24. CrossRef Medline

Tsuda M, Masuda T, Kitano J, Shimoyama H, Tozaki-Saitoh H, Inoue K (2009) IFN- $\gamma$ receptor signaling mediates spinal microglia activation driving neuropathic pain. Proc Natl Acad Sci U S A 106:8032-8037. CrossRef Medline

Vereker E, O'Donnell E, Lynch MA (2000) The inhibitory effect of interleukin- $1 \beta$ on long-term potentiation is coupled with increased activity of stress-activated protein kinases. J Neurosci 20:6811-6819. Medline

Watkins LR, Wiertelak EP, Goehler LE, Smith KP, Martin D, Maier SF (1994) Characterization of cytokine-induced hyperalgesia. Brain Res 654:15-26. CrossRef Medline

Watkins LR, Goehler LE, Relton J, Brewer MT, Maier SF (1995) Mechanisms of tumor necrosis factor- $\alpha$ (TNF- $\alpha$ ) hyperalgesia. Brain Res 692: 244-250. CrossRef Medline

Watkins LR, Hutchinson MR, Milligan ED, Maier SF (2007) "Listening" and "talking" to neurons: implications of immune activation for pain control and increasing the efficacy of opioids. Brain Res Rev 56:148-169. CrossRef Medline

Wei F, Guo W, Zou S, Ren K, Dubner R (2008) Supraspinal glialneuronal interactions contribute to descending pain facilitation. J Neurosci 28:10482-10495. CrossRef Medline

Xu J-T, Xin WJ, Zang Y, Wu CY, Liu XG (2006) The role of tumor necrosis factor-alpha in the neuropathic pain induced by Lumbar 5 ventral root transection in rat. Pain 123:306-321. CrossRef Medline

Youn DH, Wang H, Jeong SJ (2008) Exogenous tumor necrosis factor- $\alpha$ rapidly alters synaptic and sensory transmission in the adult rat spinal cord dorsal horn. J Neurosci Res 86:2867-2875. CrossRef Medline

Yu SP, Yeh CH, Strasser U, Tian M, Choi DW (1999) NMDA receptormediated $\mathrm{K}^{+}$efflux and neuronal apoptosis. Science 284:336-339. CrossRef Medline

Zhang H, Dougherty PM (2011) Acute inhibition of signaling phenotype 
of spinal GABAergic neurons by tumour necrosis factor- $\alpha$. J Physiol 589:4511-4526. CrossRef Medline

Zhang H, Nei H, Dougherty PM (2010) A p38 mitogen-activated protein kinase-dependent mechanism of disinhibition in spinal synaptic transmission induced by tumor necrosis factor- $\alpha$. J Neurosci 30:12844-12855. CrossRef Medline

Zhang L, Berta T, Xu ZZ, Liu T, Park JY, Ji RR (2011) TNF- $\alpha$ contributes to spinal cord synaptic plasticity and inflammatory pain: distinct role of TNF receptor subtypes 1 and 2. Pain 152:419-427. CrossRef Medline
Zhang RX, Li A, Liu B, Wang L, Ren K, Zhang H, Berman BM, Lao L (2008) IL-1ra alleviates inflammatory hyperalgesia through preventing phosphorylation of NMDA receptor NR-1 subunit in rats. Pain 135:232-239. CrossRef Medline

Zhong Y, Zhou LJ, Ren WJ, Xin WJ, Li YY, Zhang T, Liu XG (2010) The direction of synaptic plasticity mediated by $\mathrm{C}$-fibers in spinal dorsal horn is decided by Src-family kinases in microglia: The role of tumor necrosis factor- $\alpha$. Brain Behav Immun 24:874-880. CrossRef Medline 